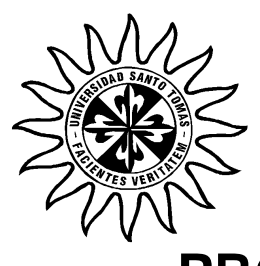

\title{
PROPUESTA DE UN SUBPROCESO EN EL SUMINISTRO DE ALIMENTOS PARA LOS INTERNOS DE LA CARCEL LA BLANCA - MANIZALES
}

ESTUDIANTE:

JUAN VICENTE CANO PARRA

DOCENTE:

ANDRES FELIPE JIMENEZ

\author{
UNIVERSIDAD SANTO TOMÁS \\ VICERRECTORÍA DE UNIVERSIDAD ABIERTA Y A DISTANCIA \\ ADMINSTRACIÓN DE EMPRESAS \\ CENTRO DE ATENCIÓN UNIVERSITARIO MANIZALES
}

MANIZALES, 24 DE NOVIEMBRE DE 2017 


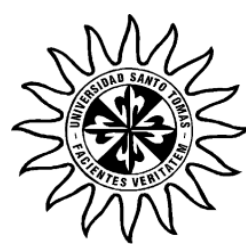

\title{
PROPUESTA PARA UN SUBPROCESO EN EL SUMINISTRO DE ALIMENTOS PARA LOS INTERNOS DE LA CARCEL LA BLANCA - MANIZALES
}

ESTUDIANTE:

JUAN VICENTE CANO PARRA

DOCENTE:

ANDRES FELIPE JIMENEZ

\author{
UNIVERSIDAD SANTO TOMÁS \\ VICERRECTORÍA DE UNIVERSIDAD ABIERTA Y A DISTANCIA \\ ADMINSTRACIÓN DE EMPRESAS \\ CENTRO DE ATENCIÓN UNIVERSITARIO MANIZALES
}

MANIZALES, 11 DE FEBRERO DE 2019 


\section{TABLA DE CONTENIDO}

INTRODUCCIÓN. 9

ABSTRACT. .jError! Marcador no definido.

PALABRAS CLAVES jError! Marcador no definido. JUSTIFICACIÓN

OBJETIVO GENERAL

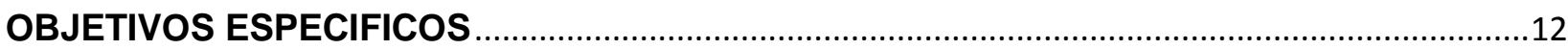

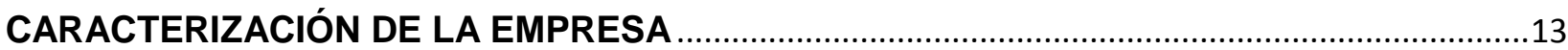

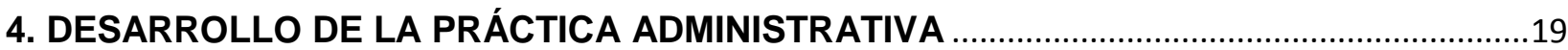

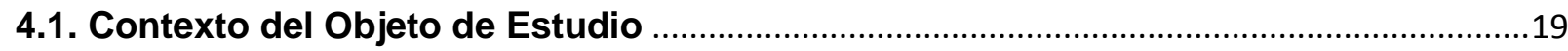

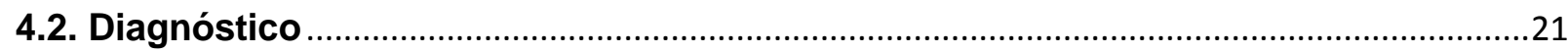

4.3. Planteamiento y Formulación del Problema a Solucionar ............................................32

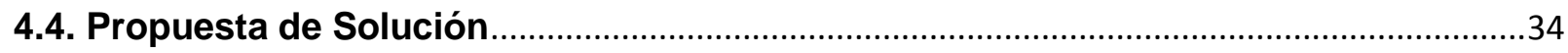

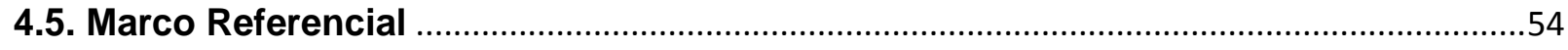

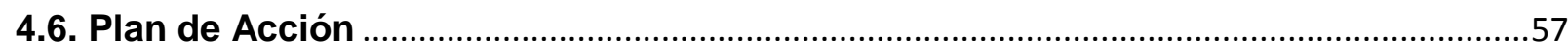

4.7. Integración con el Balanced Score Card...................................................................65

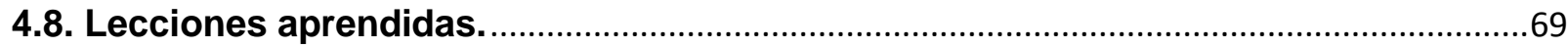

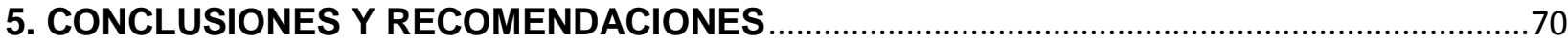

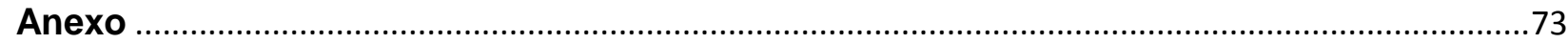




\section{TABLA DE ILUSTRACIONES}

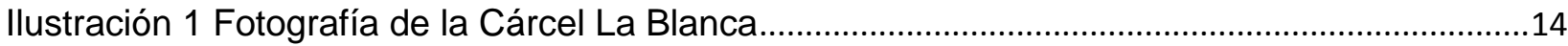

Ilustración 2 Ingreso materia Prima a la Cárcel............................................................................14

Ilustración 3 Distribución interna de la planta de operación ...........................................................16

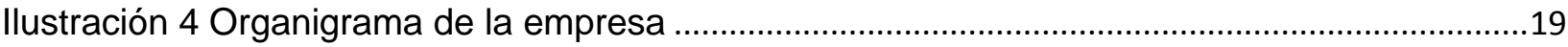

Ilustración 5 Encuesta preparación de alimentos ............................................................................27

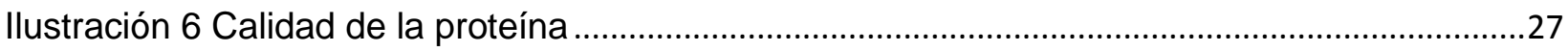

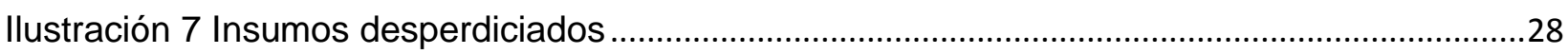

Ilustración 8 Como mejorar la alimentación ......................................................................................29

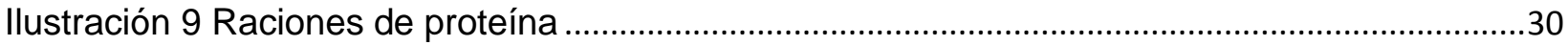

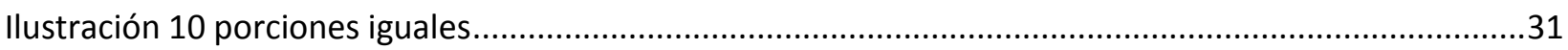

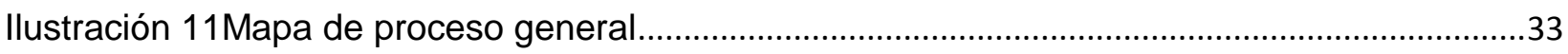

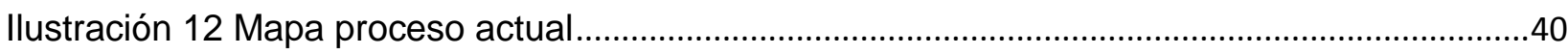

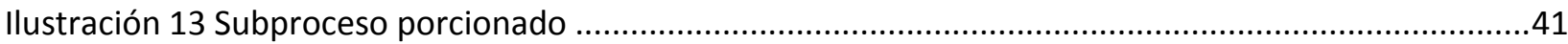

Ilustración 14 Flujo grama de producción.................................................jError! Marcador no definido.

Ilustración 15 solución a proceso operativo ........................................................................................43

Ilustración 16 caracterización del proceso .................................................jError! Marcador no definido.

Ilustración 17 caracterización de un subproceso ......................................jError! Marcador no definido.

Ilustración 18 proceso toma de decsiones ..............................................jError! Marcador no definido.

Ilustración 19 Estudio de tiempo y movimiento .........................................Error! Marcador no definido.

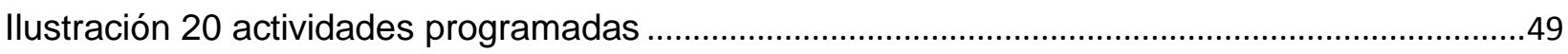

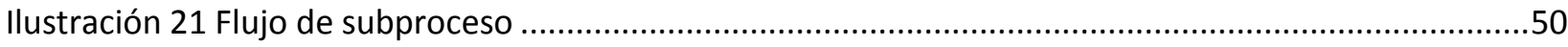

Ilustración 22 matriz de riesgos ............................................................Error! Marcador no definido.

Ilustración 23 Plan de mejoramiento ........................................................ Error! Marcador no definido.

Ilustración 24 El balanced scored card...........................................................jError! Marcador no definido.

Ilustración 25 Impacto del proyecto ............................................................. EError! Marcador no definido.

Ilustración 26 matriz de riesgos al implementar ......................................jError! Marcador no definido.

Ilustración 27Indicador de cumplimento ................................................. Error! Marcador no definido.

Ilustración 28 Integración del Balanced score card .......................................... Error! Marcador no definido.

Ilustración 29 Medición impacto proyecto .................................................... Error! Marcador no definido. 


\section{RESUMEN EN ESPAÑOL}

El trabajo de grado, se inicia con la búsqueda y análisis de los problemas más relevantes que se presentan en el área productiva de la empresa Liber SAS, que tiene subsede dentro de las Instalaciones del Centro Penitenciario y Carcelario de Mediana Seguridad para Varones de la ciudad de Manizales. Los productos que oferta la empresa presentan inconsistencias en cuanto a la presentación, tamaño y peso al igual que las falencias en cuanto a las condiciones fitosanitarias que están intrínsecamente vinculadas al área de preparación de alimentos.

La alternativa que se plantea como mejor solución está enfocada a la creación de un subproceso que dependa del proceso de preparación de alimentos, donde se deben mejorar y tecnificar las herramientas de trabajo, es importante para esta labor la compra de una sierra[DAE1] eléctrica tipo industrial, para aligerar el proceso de separación de carnes de manera homogénea, presentándolas de manera uniforme, garantizando el peso adecuado y las condiciones de salubridad exigidas por ley.

A esta conclusión se llega luego de realizar una investigación que analiza las encuestas realizadas a los internos del penal, destacando el nivel de insatisfacción sobre la carne que consumen que alcanza un $96 \%$ y le atribuyen el $100 \%$ de las enfermedades gastrointestinales a la mala calidad de la proteína. Las recomendaciones que se ofrecen están basadas en el éxito que tienen herramientas como la sierra, en empresas de relevancia nacional como Frisby y carnecol, donde el desperdicio alcanza el $4 \%$ y en Liber llega al $37 \%$. 


\section{ABSTRACT}

The work of degree, begins with the search and analysis of the most relevant problems that arise in the productive area of the company Liber SAS, which has a subsite within the facilities of the Penitentiary Center and Prison of Medium Security for Males of the city of Manizales. The products offered by the company present inconsistencies in terms of presentation, size and weight as well as the shortcomings in terms of phytosanitary conditions that are intrinsically linked to the area of food preparation.

The alternative that is proposed as the best solution is focused on the creation of a subprocess that depends on the food preparation process, where the work tools must be improved and technified, it is important for this work to buy an industrial type electric closure, to lighten the process of meat separation in a homogeneous way, presenting them in a uniform way, guaranteeing the right weight and the health conditions required by law.

This conclusion is reached after carrying out an investigation that analyzes the surveys made to the inmates of the prison, highlighting the level of dissatisfaction about the meat they consume that reaches $96 \%$ and attribute $100 \%$ of gastrointestinal diseases to poor quality of the protein. The recommendations that are offered are based on the success of tools such as the sierra, in companies of national importance such as Frisby and carnecol, where waste reaches $4 \%$ and in Liber it reaches 37\%. 


\section{PALABRAS CLAVES EN ESPAÑOL}

Proceso

Producción alimenticia

Subproceso

Mejoramiento continúo

KEYWORDS

Process

Food production

Subprocess

Continuous improvement 


\section{INTRODUCCIÓN}

El trabajo de grado está basado en la Práctica Administrativa II, pues se requiere estudiar y trabajar en la producción por procesos, buscar estrategias que puedan implementarse y que a la empresa estudiada, le signifique una disminución de las perdidas y que para los consumidores se refleje en el mejoramiento de la alimentación y de paso en la calidad de vida, buscando precisamente estar en mejora continua.

Se requiere de una alternativa que mejore la alimentación de los internos del Centro Penitenciario de Mediana Seguridad de la ciudad de Manizales y que son producidos por la empresa Liber SAS, que tiene una subsede dentro de las instalaciones del establecimiento carcelario. En el proceso de manipulación de alimentos, se detectan irregularidades en la proteína suministrada en las raciones diarias, por fallas en los procedimientos que se realizan en la organización que presta el servicio a la entidad pública.

La problemática se agudiza debido a los recientes cambios climáticos, que traen consigo un aceleramiento progresivo de la temperatura en la región, esto aumenta la probabilidad de contaminar los alimentos ofertados por Liber SAS, pues deben ser manipulados en el proceso denominado manipulación de alimentos, con técnicas inapropiadas y sin respetar la cadena de frio, de esta manera pierden sus propiedades y valor nutricional.

Después de analizar y organizar los datos obtenidos de la recolección de información realizada mediante la aplicación de técnicas como la encuesta y la observación, pues como dice (BERNAL, 2010, pág. 259) "la técnica más adecuada para la recolección de la información es la observación", se dedicaron varios años, a la compilación de información, debido a las normas restrictivas que se manejan dentro del Centro Penitenciario y Carcelario de Mediana Seguridad para varones de la ciudad de Manizales, Caldas, donde me encuentro en calidad de recluso; es allí donde se muestra que el $96 \%$ de los encuestados están insatisfechos de la alimentación que reciben; el ingrediente que solicitan sea cambiado o mejorado es 
el de la proteína, a la vez manifiestan que el $100 \%$ de las enfermedades gastrointestinales están asociadas a la mala calidad de la carne.

De otra parte se muestran datos obtenidos en la página oficial de empresas como Frisby y Carnecol, donde utilizan la sierra eléctrica en el procedimientos de corte de porciones y el desperdicio producido es del $5 \%$ para el año 2016, mientras en Liber SAS donde no se tiene este procedimiento el desperdicio llega al $37 \%$ en promedio para los años 2016 y 2017, según datos registrados en el libro de contabilidad de la empresa.

La alternativa de solución que se sugiere para mejorar. Es la creación de un sub proceso, que dependa del proceso de manipulación de alimentos, en esté se deben usar herramientas como la sierra eléctrica que porcione las carnes de manera homogénea, deben quedar separadas, contadas y guardas en el cuarto frio, de esta manera la empresa garantiza calidad igualdad.

En el presupuesto de costos se muestra como si Liber SAS, no invierte en herramientas tecnológicas ni de capacitación de su personal operativo, le representa pérdidas y aumento de los costos de producción y deficiencias en la calidad de comida suministrada a los Penados de la ciudad de Manizales. En síntesis se requiere mejorar para mostrar eficiencia y eficacia con los bienes y servicios que vende, lo que es, fundamental en el poder de competitividad que tienen las organizaciones, dentro de un mundo cada vez más complejo y exigente. 


\section{JUSTIFICACIÓN}

El trabajo de grado se enfoca en la búsqueda de los problemas que afectan el área de producción de la empresa Liber SAS, la cual suministra la alimentación a los internos del Centro Carcelario de la ciudad de Manizales, pues son constantes las pérdidas de materia prima y la irregularidad en peso y tamaño del producto terminado, principalmente en la proteína suministrada en las raciones diarias, por fallas en los procedimientos que se realizan en la manipulación de los alimentos.

La problemática se agudiza debido a los recientes cambios climáticos, que traen un aumento progresivo de temperaturas en la región, esto ocasiona probabilidad de contaminar los productos ofertados por Liber, pues deben ser manipulados en el proceso denominado preparación de alimentos, con técnicas inapropiadas y sin respetar la cadena de frio, de esta manera pierden sus propiedades y valor nutricional.

Así, el presente trabajo permitiría mostrar la necesidad de crear un subproceso que corrija las irregularidades presentadas, a la vez profundizar los conocimientos teóricos sobre los procesos, estudio de tiempos y movimientos. La adaptación en la parte operativa puede generar un beneficio tanto para Liber como para los clientes consumidores

De otra parte ofrecer una mirada integral a la responsabilidad social empresarial con las clases sociales vulnerables, sin descartar la razón de ser de toda organización y es el del crecimiento económico sostenible, ayudando de una manera indirecta a los penados con el mejoramiento de su dieta, respetando de esta manera su dignidad humana, ya que la alimentación adecuada es la base tanto de la salud física como la mental, pudiendo ser esta una de las razones de tantas enfermedades y desequilibrios emocionales que presentan los consumidores de la empresa en mención. 


\section{OBJETIVO GENERAL}

- Proponer un subproceso dentro del proceso de suministro de alimentos, para porcionar de manera adecuada la alimentación para los usuarios de la Cárcel La Blanca de Manizales -Caldas.

\section{OBJETIVOS ESPECIFICOS}

- Analizar los problemas operativos de la empresa Pro alimentos Líber S.A.S., a fin de presentar alternativa de solución.

- Identificar los procesos operativos de la empresa Liber para determinar la mejor solución en la implementación de un nuevo subproceso que permita la satisfacción del consumidor.

- Diseñar un subproceso en el proceso de suministro de alimentos para La satisfacción del usuario de la Cárcel La Blanca en la ciudad de Manizales-Caldas. 


\section{CARACTERIZACIÓN DE LA EMPRESA}

\section{Proalimentos tiber S.A.S}

Calidad y buen servicio

Proalimentos Líber S.A.S: Empresa dedicada a la prestación de servicios de alimentación, alojamiento y recreación. La organización tiene presencia en Perú y Colombia, en este último su sede principal está ubicada en la Carrera $10620 \mathrm{C}$ 25, Bogotá, Distrito Capital. Teléfono (571) 2602887 - 260 2893. El nombre de la empresa proviene de las siglas que indican las iniciales de los fundadores de la empresa, tiene origen familiar y luego constituido como Sociedad por Acciones Simplificada.

La subsede objeto de estudio, está localizada en la región del Eje Cafetero, ciudad de Manizales, dentro de la Penitenciaria de Mediana Seguridad de varones "La Blanca", ubicada en el kilómetro 2 vía panamericana, cuenta con una planta física de aproximadamente 240 metros cuadrados, donde se preparan los alimentos para 1497 internos (información suministrada por el área administrativa de Liber). Este servicio se ofertó y contrato mediante licitación pública con la Unidad de Servicios Penitenciarios y Carcelario (USPEC), adscrita al Instituto Nacional Penitenciario y carcelario (INPEC).

RAZON SOCIAL: Líber S.A.S, es una empresa de servicios, se dedica a la alimentación de la población penada en algunas regiones del país, con asiento en la Cárcel "la Blanca" de la ciudad de Manizales, dirección y sede principal está en la ciudad Bogotá. El inicio como empresa fue en la década anterior, la empresa era conocida por la prestación de servicios de refrigerios a planteles educativos en la región andina del país. 
OBJETO SOCIAL: Producir y comercializar alimentos para la población en estado de reclusión y eventos empresariales al mejor precio acorde con los mercados, buscando el bienestar y la nutrición de todos los clientes

\section{Ilustración 1 Fotografía de la Cárcel La Blanca}

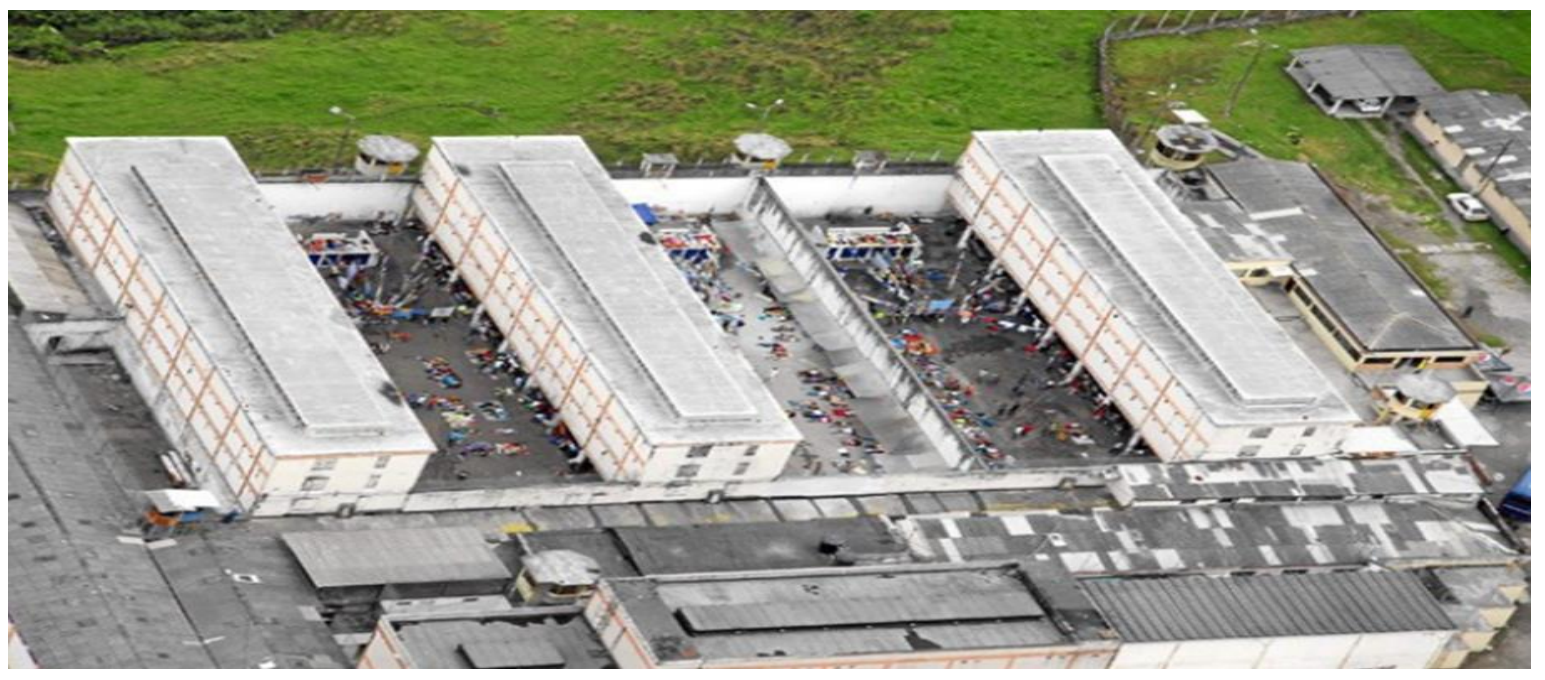

Fuente: Diario La patria 2017

En esta fotografía muestra, la periferia de la Cárcel "La Blanca" donde se encuentran tres torres de igual tamaño con cinco pisos, en la parte baja están los pasillos de 120 metros de profundidad, justo en la mitad esta las bodegas y todo el andamiaje de la empresa Proalimentos Liber S.A.S.y por la parte anterior el cuarto frio donde se almacenan las materias primas para la preparación de los alimentos.

Con respecto a las restricciones de orden legal que se presenta en la portería principal, donde las requisas son minuciosas, demoradas y obligatorias, estas son algunas de las particularidades que se viven al interior de la penitenciaria, por ende la organización utiliza con ingenio las canastas de icopor a fin de lograr evitar maltrato a las materias primas y de otra parte garantizar la cadena de frio que requieren los cárnicos. 


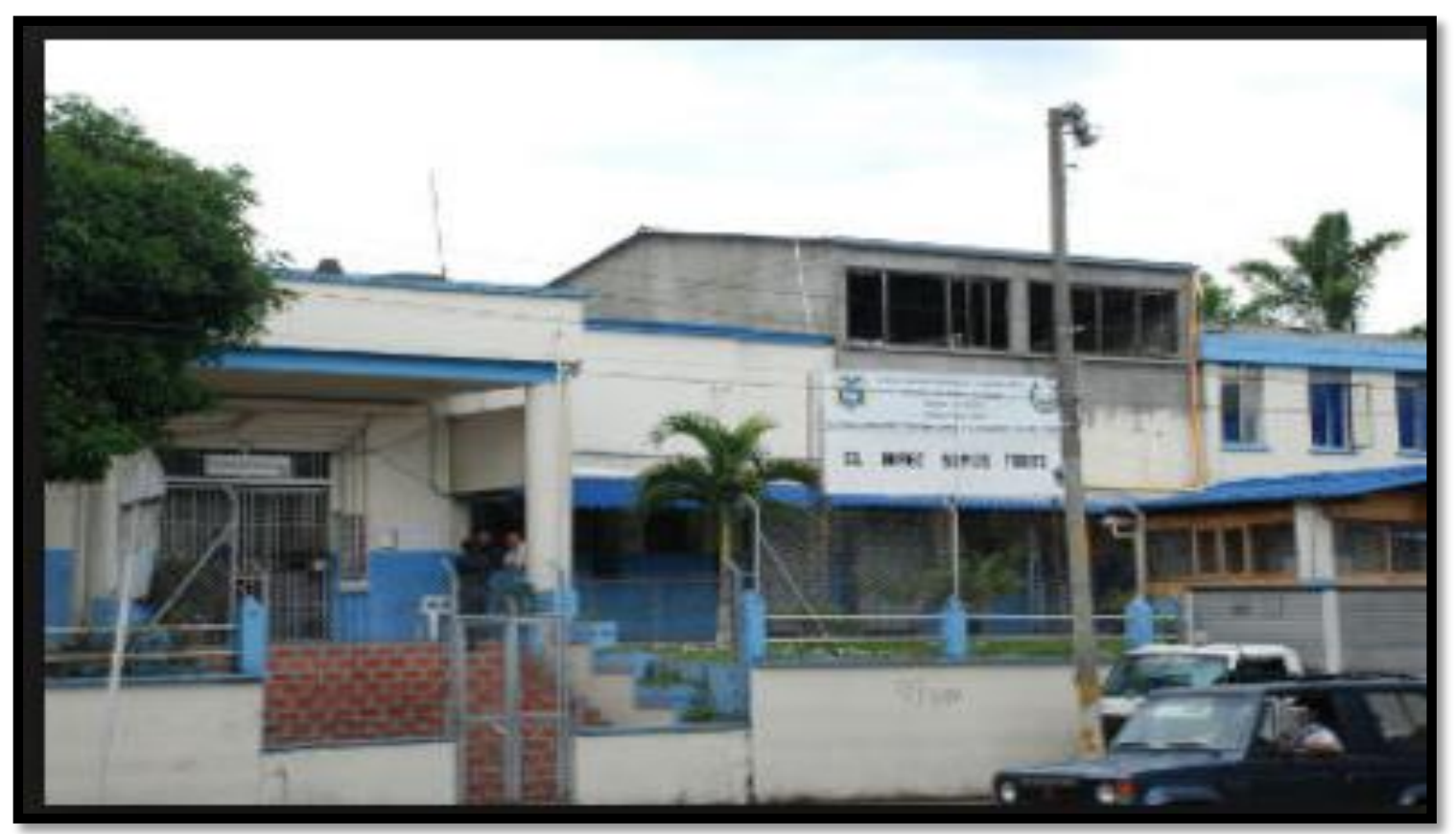

Fuente: Diario la Patria 2018

En la ilustración que antecede se muestra la panorámica de la entrada principal de la Penitenciara, con tres puertas que distan 5 metros cada una y entre ellas hay la misma cantidad de requisas o filtros para el ingreso de materia prima para LIber SAS. 


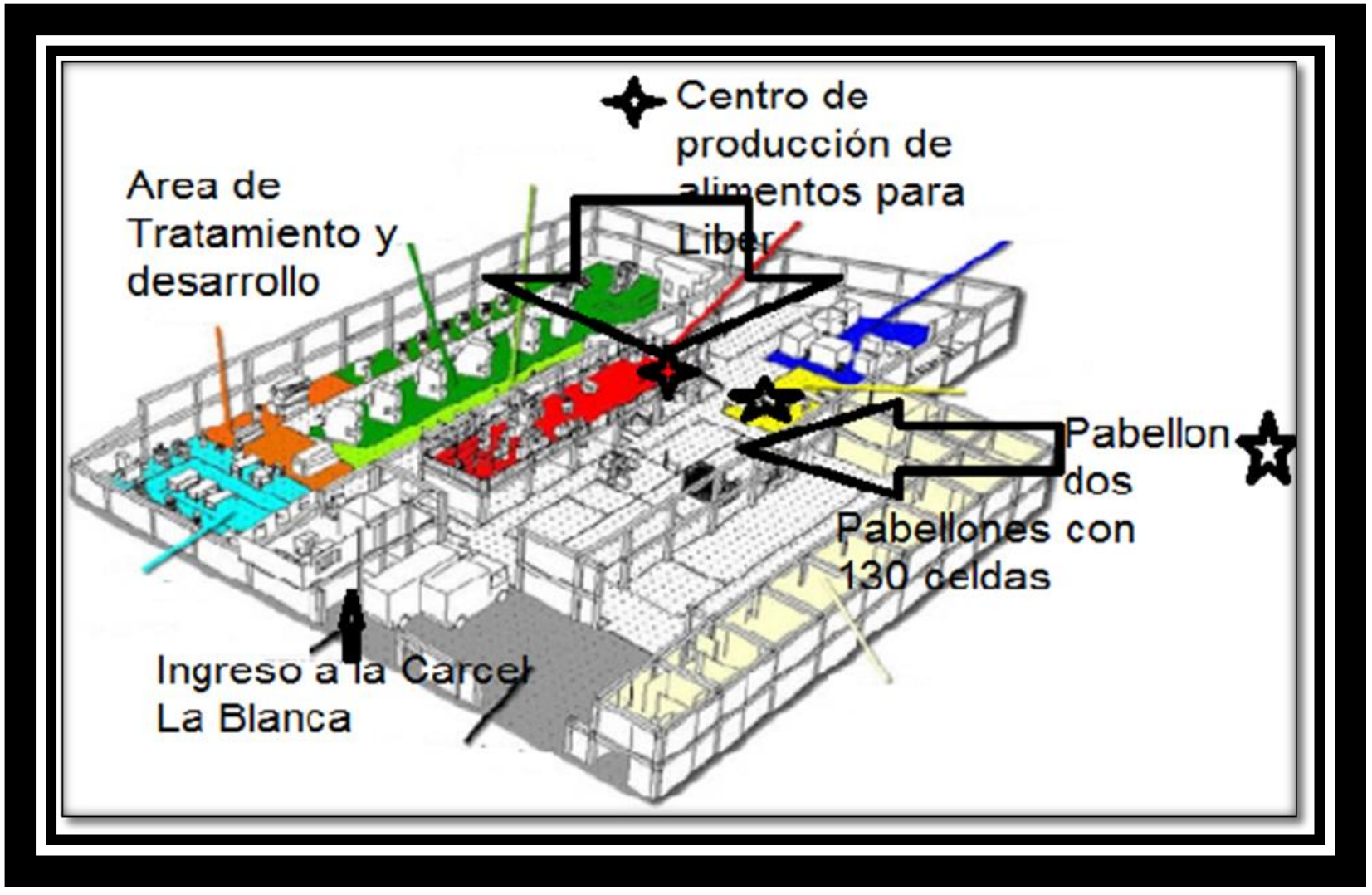

Fuente: Elaboración propia

En esta ilustración, se observa de color rojo el espacio donde se encuentra el área productiva de la empresa Liber SAS, existen tres ingresos al cuarto frio, por el frente se encuentran los pabellones donde están los penados; la distancia entre bodegas y la entrada principal; se descarga la mercancía que es traída en vehículos y sigue el recorrido en carretas, para recorrer los 150 metros que existen hasta el cuarto frio

Por otro lado, el perfil del cliente consumidor para el cual es preparada la alimentación es la población carcelaria es masculina, está dividida en 6 pabellones y en el numero 5A se encuentran la comunidad LGTBI, con un nivel de educación básica primaria, exceptuando los penados del pabellón número $5 \mathrm{~B}$, el cual es habitado por exfuncionarios públicos y personalidades de influencia política administrativa en la región, con un nivel de estudios superiores.

En los restantes pabellones el estrato socioeconómico de la población es de estratos uno y dos, provenientes en su mayoría de barrios periféricos, especialmente de 
las comunas 3 y 5 de la ciudad de Manizales, con el $55 \%$ de los reclusos, otro $10 \%$ las otras comunas; el municipio de Chinchiná aporta el 17\%, los demás pueblos del departamento de Caldas $13 \%$ y el $5 \%$ para la población de otros departamentos. (esto según datos aportados por la oficina de Tratamiento y Desarrollo de la Cárcel La Blanca)

\section{Edad:}

Según los datos suministrados por el área de Tratamiento y Desarrollo del penado la edad de la población carcelaria se divide en cuatro grandes grupos, destacando como hecho significativo el de las personas jóvenes o sea de edades de 18 a 25 años, representa el $35 \%$, a continuación, se presenta una tabla con la cantidad y porcentaje de la población:

Tabla 1 Edad de los penados

$\begin{array}{lll}\text { Edad en años } & \text { Numero } & \text { Porcentaje } \\ \text { De } 18-24 & 490 & 33 \% \\ \text { De } 25-30 & 380 & 25 \% \\ \text { De } 31-40 & 277 & 18 \% \\ \text { Más de } 40 \text { años } & 250 & 16 \% \\ \text { Total } & 1497 & 100 \%\end{array}$

Fuente: Información de la oficina de Tratamiento y desarrollo.

Valores Corporativos:

- $\quad$ Solidaridad: nos sentimos comprometidos con la población vulnerable y asumimos que nuestras acciones afectan a los demás.

- Participación: Somos una organización democrática, donde cada miembro tiene incidencia en la toma de decisiones e igualdad de oportunidades. 
- $\quad$ Equidad: Facilitamos el desarrollo integral de todos los colaboradores, con la distribución justa e imparcial de los beneficios estipulados en contratos de trabajo.

- Honestidad: realizamos todas las operaciones con trasparencia y rectitud.

- Lealtad: Somos fieles al cumplimiento de las directrices institucionales y buscamos su desarrollo y permanencia en el tiempo.

- Responsabilidad: Obramos con seriedad, en consecuencia, con nuestros deberes y derechos para con los clientes, acorde con nuestro compromiso.

- Respeto: Escuchamos, entendemos y valoramos al otro, buscando armonía en las relaciones interpersonales, laborales y comerciales.

- Mística: Realizamos nuestro trabajo bien desde el principio, con la convicción de entregar lo mejor.

- Confianza: Cumplimos con lo prometido al ofrecer los mejores productos y servicios a un precio justo y razonable.

Misión: Somos una empresa líder del sector alimenticio que posibilita el desarrollo y bienestar de los consumidores clientes y de trabajadores, a través de una oferta integral y oportuna de productos y servicios, como la mejor opción en la relación calidad-precio, para satisfacer sus necesidades en el contexto nacional, con proyección internacional. Para ello contamos con la tecnología apropiada y un talento humano visionario, comprometido con los valores corporativos, la preservación del medio ambiente y la construcción de un mejor País. (Liber, 2017)

Visión: Seremos una organización altamente comprometida con la expansión de la producción del sector las comidas y de las actividades complementarias para el desarrollo integral de los clientes consumidores y de las regiones donde realizamos gestión con procesos innovadores, cumpliendo los más estrictos estándares de calidad, productividad y competitividad para satisfacer las necesidades de nuestros clientes en los mercados nacionales e internacionales. (Liber, 2017) 


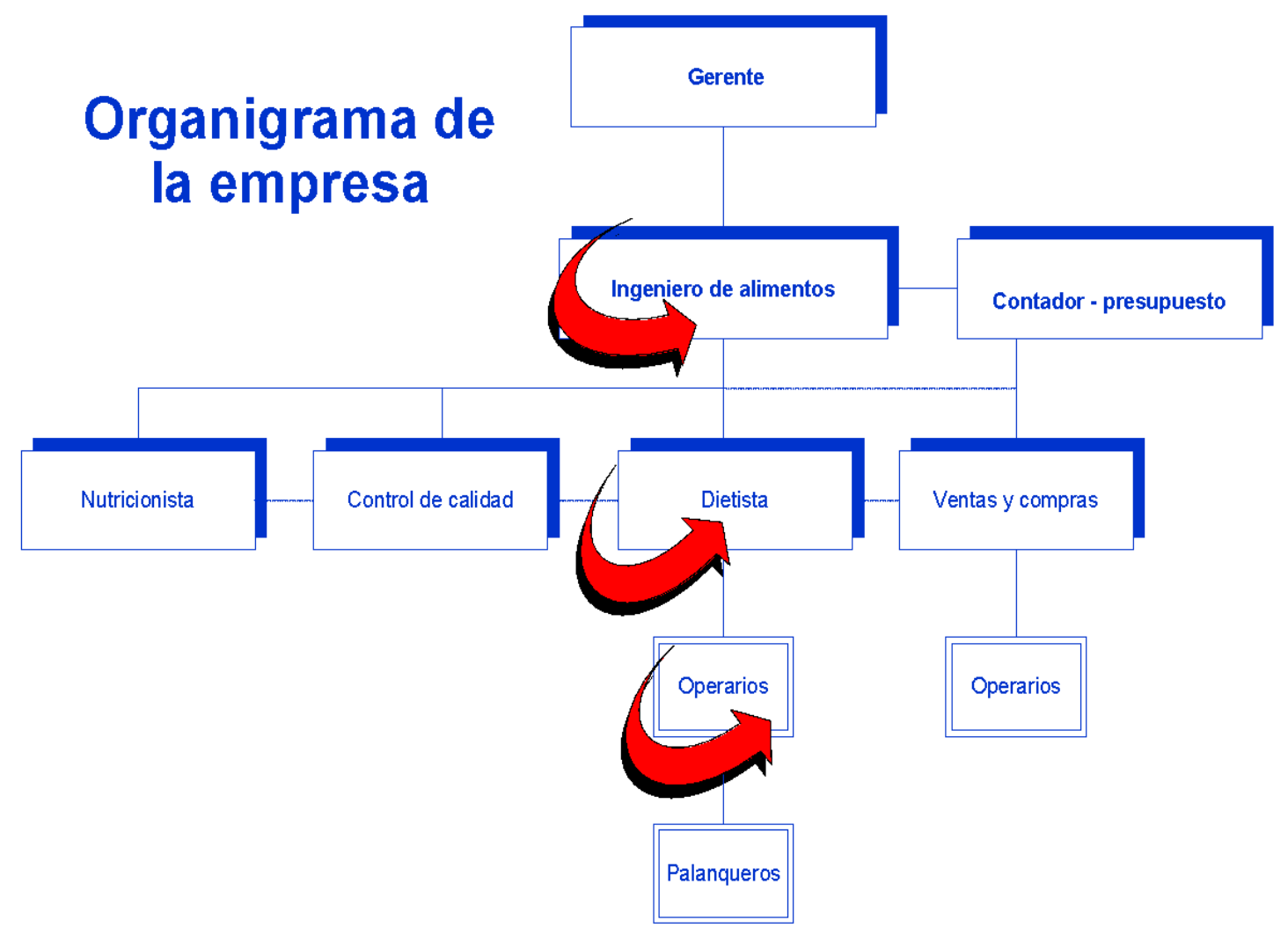

Fuente: Elaboración propia

Esta es la ilustración que muestra el diagrama de la organización que es de tipo vertical donde las decisiones de carácter estratégico son tomadas por la gerencia, el ingeniero de alimentos es el encargado de direccionar la parte operativa de la empresa en la ciudad de Manizales y de él dependen los operarios y los palanqueros, Los que laboran en la preparación de los alimentos.

\section{DESARROLLO DE LA PRÁCTICA ADMINISTRATIVA}

\subsection{Contexto del Objeto de Estudio}

El trabajo de grado está basado en la Práctica Administrativa II, (producción por procesos), enfatiza la búsqueda de una solución al problema que se presenta en el manejo de las proteínas como base fundamental de los productos que oferta la empresa prestadora de servicios de alimentos Líber S.A.S. con sede en la Cárcel 
de Varones de Manizales, trabajo dirigido por docentes de la Universidad Santo Tomas, facultad de ciencias y tecnologías.

La práctica administrativa se enmarca en el análisis y observación de los procesos productivos, además de entrevistas a los directivos de la empresa estudiada, ya que a través de estos se toma una noción global y se recibe la descripción de los procesos productivos. Estos son el soporte y focalización.

El proceso seleccionado se localiza en el almacén, proceso Organización de alimentos, se detectan problemas en el manejo y manipulación de estos, que trae con sigo embotellamientos y retrasos, estas falencias riñen con las políticas y los objetivos trazados por la organización; como se referencia "las restricciones mayores o iguales se denominan restricciones de benéfico, ya que su forma es el nivel alcanzado para algún beneficio debe ser mayor o igual que el nivel mínimo aceptable del mismo. A menudo expresan metas que fija la dirección". (Hillier \& Hillier, 2010, pág. 93)

Por otra parte se analizan las debilidades que presenta el área de manipulación de alimentos, se crean conflictos a causa del embotellamiento que se forma por causas diversas como almacenar y procesar materia prima, estos son de dos tareas distintas porque el almacén es el encargado de la parte de bodegaje por eso al respecto se cita lo siguiente:

El almacén es el corazón logístico de toda organización. Cualquier ineficiencia en éste área repercute, de manera directa, sobre el resto de actividades logísticas de la empresa e, indirectamente, en muchos otros departamentos de la misma: producción (si la empresa es manufacturera), compras y aprovisionamiento, ventas, etc. De ahí la importancia de las funciones del jefe de almacén". ( (Di Marco, 1935, pág. 121)

El subproceso que se sugiere es el de manejo y selección de materia prima que para el caso es el de la separación de porciones de carnes, porque requiere de agilidad y optimización del tiempo a fin de respetar la cadena de frio, sobre 
este punto (Di Marco, 1935, pág. 77), manifiesta "preparación y manejo requiere los siguientes pasos":

- $\quad$ Preparar la orden de picking o extracción (emitida generalmente por el almacén).

- Recorrer el almacén hasta los puntos de extracción (la longitud y duración de estos recorridos dependerá de la cantidad de líneas de pedido o variedad de surtido de los mismos, de la zonificación del almacén, del nivel de exactitud de la situación de los productos a extraer, etc.,).

- $\quad$ Extraer la mercancía de su ubicación.

- Transportar la misma hasta la zona de expedición

\subsection{Diagnóstico}

La empresa donde se realizan el presente trabajo, presenta perdidas de materia prima "que alcanzan un $37 \%$ del total de compras de proteína" según el reporte del área de producción de Liber S.A.S. para el primer semestre del año 2017, por ende se requiere con urgencia realizar una investigación que busque el origen de la problemática en la organización, empresa presentada de servicios de alimentos para la población carcelaria de la ciudad de Manizales, enfocando toda la atención en los problemas de producción. Que conlleva a una disminución lenta pero progresiva en sus ventas tal como lo revelan los datos de (Sarmiento, 2017, pág. 13), así:

"Los métodos usados por la empresa para producir y distribuir los alimentos tienen falencias siendo poco eficiente en la prestación de servicios que vende, haciendo que su imagen ante el consumidor cliente sea la de insatisfacción y desaprobación", lo que desencadena limitantes de competitividad. La infraestructura de la cárcel, según datos de la reseña histórica, "fue diseñada para albergar a 640 internos con su respectivo casino, pero en la actualidad existe un 
hacinamiento del 132\%", (según la minuta de registro de internos ${ }^{1}$ ) esto dificulta la prestación de los servicios de alimentación de Proalimentos Liber, supera la capacidad instalada y teniendo dificultades en la utilización de la Planta de producción tal como lo establece la Resolución 2674 de 2013, expedida por el Ministerio de Salud.

La empresa tiene dificultades en la producción del producto terminado, sobre el particular "los alimentos que se fabriquen, envasen o importen para su comercialización en el territorio nacional, requerirán de notificación sanitaria, permiso sanitario o registro sanitario, según el riesgo de estos productos en salud pública" (Salud, 2013, pág. 2).

Los reportes sobre devoluciones y reportes de inconformidad alimentaria no están de conformidad con la reglamentación que expida el Ministerio de Salud y Protección Social que vigila, controla y establece los requisitos y condiciones bajo los cuales el Instituto Nacional de Vigilancia de Medicamentos y Alimentos INVIMA, como autoridad sanitaria del orden nacional, deberá expedir para esta empresa los registros, permisos o notificaciones sanitarias.

La organización está en curso de obtener el permiso sanitario expedido por la autoridad competente en Colombia, es el Instituto Nacional de Vigilancia de Medicamentos y Alimentos (INVIMA), pero el problema de hacinamiento de los centros carcelarios, "la situación de las cárceles se le salió de las manos al gobierno nacional, no hay espacio disponible para alojar a los 170.000 reclusos que en la actualidad hay en Colombia" (Samper, 2014, pág. 23).

Esta problemática representa un desafío para la empresa, que al momento no estudia los tiempos y los movimientos, tampoco cuantifica los inventarios que deben ser cuantificados para tener una correcta administración y por ende los productos no son entregados en los tiempos establecidos y con la calidad idónea al cliente. Los mecanismos utilizados en la preparación de los alimentos no cumplen con Buenas Prácticas De Manufactura. (BPM)

\footnotetext{
${ }^{1}$ Minuta, es el libro del INPEC que lleva control de los presos día a día. Es llevado por el guardián de turno quien
} registra todas las novedades. 
También se encontraron deficiencias respecto a las BPM, son los principios básicos y prácticos generales de higiene en la manipulación, preparación, elaboración, envasado, almacenamiento, transporte y distribución de alimentos para consumo humano, con el objeto de garantizar que los productos en cada una de las operaciones mencionadas cumplan con las condiciones sanitarias adecuadas, de modo que se disminuyan los riesgos inherentes a la producción.

La organización no cuenta con oficina de Talento humano, se recomienda a la par de la creación del sub proceso, trabajar en ésta área para reforzar el proceso operativo, encargándose de seleccionar equipos de trabajo cualificados, que cumplan las exigencias del mercado.

El servicio de alimentación no cuenta con el Sistema de Riesgos y Análisis de Puntos Críticos (HACCP) que presta Pro alimentos Líber S.A.S. a los internos de la Cárcel la Blanca, se realiza en un escenario muy singular que reúne características únicas en el mercado, requieren ser administradas con mucho profesionalismo y ética. Por ende, es de gran importancia sugerir soluciones a los problemas que surgen a la hora de distribuir los alimentos a los distintos "pabellones"2 del penal.

Pro alimentos Líber S.A.S. es una empresa que maneja un tipo de mando jerárquico o de organización vertical, se caracteriza por tener a la cabeza un gerente que toma las decisiones de manera autónoma, existen líneas claras de autoridad y una tendencia estricta de control, lo que puede conducir a una alta presión y estrés de los operarios. En general, la organización está compuesta por departamentos muy pequeños, lo que permite que los administradores supervisen de cerca y controlen las actividades de sus subordinados. Cada capa de la organización informa al que está directamente encima de él, recorriendo todo la cadena hasta la alta dirección. No se presenta oportunidad de escalar a otro nivel de la organización, en el cuadro se muestra otros problemas de este tipo de mando:

\footnotetext{
2 Pabellon: Patio independiente donde se alojan reclusos.
} 
Iustración 5 organización

\section{ORGANIZACIÓN VERTICAL}

Excesiva separación entre conducción y operación

Reducida interación/ comunicación

Baja identificación con objetivos centrales y desmotivación

\section{Decisiones lentas}

\section{Dilución de responsabilidades}

\section{Fragmentación de procesos}

\section{Objetivos sectoriales en contravia con las politicas.}

Fuente: Elaboración propia.

En la ilustración se observa como la excesiva separación entre la conducción gerencial y la operativa hacen que las ordenes no sean acatadas de conformidad con las normas o que las directivas no se enteren de los conflictos y su origen en el área de producción; como no existe una adecuada comunicación se pierde el flujo de comunicación y todo conlleva a que las políticas de la empresa se distorsionen.

Parte del dictamen presentado es gracias a La información recolectada de primera mano, con el instrumento denominado encuestas (anexos) a los internos de los diferentes "pabellones" de la penitenciaria de Manizales. Arroja el nivel de insatisfacción que tienen con respecto a la proteína que reciben es del $99 \%$; también le atribuyen los reclusos que la mala calidad de la comida es la fuente principal de enfermedades y intoxicaciones que a diario se presentan dentro del penal con un $92 \%$.

La labor realizada en esta investigación científica, está basada en el método inductivo "...utiliza el razonamiento para obtener conclusiones que parten de hechos particulares aceptados como válidos, para llegar a conclusiones cuya 
aplicación sea de carácter general. El método se inicia con un estudio individual de los hechos y se formulan conclusiones universales que se postulan como leyes, principios o fundamentos de una teoría". (BERNAL, 2010, pág. 59)

La metodología adoptada describe características muy particulares de pro alimentos Liber S.A.S. porque sus problemas en el área productiva, brindan la oportunidad de lograr soluciones que trasciendan en el mercado laboral a otras empresas que enfrenten dificultades de la misma índole, desde el punto de vista de su producción.

De otro lado se menciona como el diagnostico aquí presentado esta respaldado por un tipo de investigación descriptiva la cual como su nombre lo indica tiene como objeto el describir una situación en particular y como señala (BERNAL, 2010, pág. 113) al citar a Cerda (1988) "tradicionalmente se define la palabra describir como el acto de representar, reproducir o figurar a personas, animales o cosas, se debe describir aquellos aspectos más característicos, distintivos y particulares ..."

Como una de las principales características de la investigación descriptiva es la de utilizar técnicas como encuestas, entrevistas y observación para la búsqueda de uno de los problemas más relevantes en los procesos operativos de Proalimentos Liber. Entonces se hace necesario saber de antemano cual va a ser el tamaño de representatividad de la muestra, recordando "la validez de un experimento depende, en alto grado, de la representatividad de la muestra de participantes con los que se lleva a cabo el experimento. Por ello, es necesario que la muestra con que se realice el experimento sea sistemáticamente estimada y seleccionada para que haya representatividad de sus resultaos y los mismos puedan generalizarse”. (BERNAL, 2010, pág. 149)

Para definir el tamaño de la muestra se usa el método probabilístico, a través del muestreo aleatorio simple, porque el conjunto de la población carcelaria, todos tienen las variables que se desean medir, como es una población finita (se conoce el numero $\mathbf{N}$ total de la población) entonces se utiliza la siguiente formula 


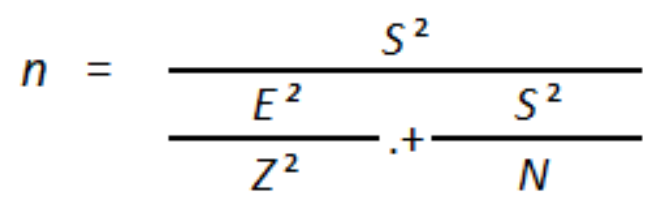

Donde:

$N$ : $\quad$ Numero total de reclusos en la Cárcel de varones "La Blanca" de la ciudad de Manizales, son 1490.

$n$ : Tamaño necesario de la muestra de personas recluidas en la Penitenciaria "La Blanca".

Z: Nivel de confianza o margen de confiabilidad alto, utilizando la tabla es = 1,96. o $95 \%$ de confianza.

$S$ : $\quad$ Desviación estándar de la población es =7 personas.

E : Error de estimación, como la población es homogénea se toma un rango del $5 \%$

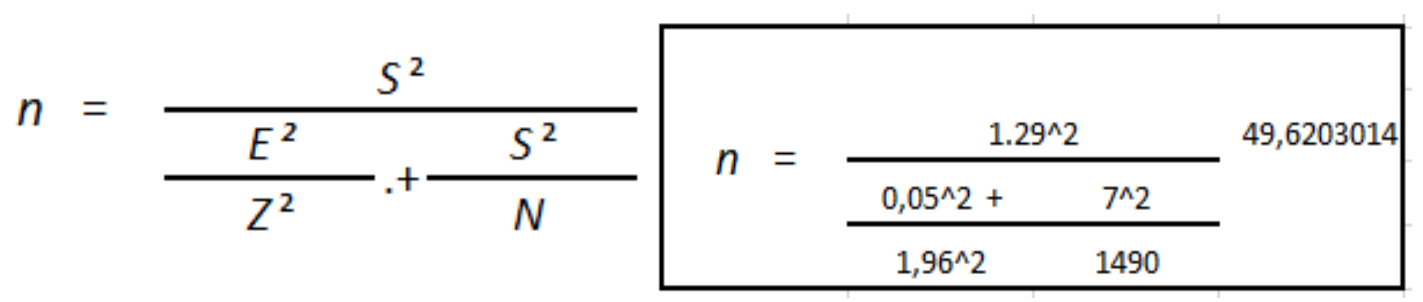

Al encontrar $\boldsymbol{n}=$ a 50 personas, entonces este es el número total al cual se realiza la encuesta en la Cárcel, pues como ya se mencionó, esta es la muestra requerida para una población de 1490 personas, con nivel de confianza del 95\% y estándar de error del 5\%. Y los datos porcentuales de la encuesta se ordenan y relacionan a continuación. 


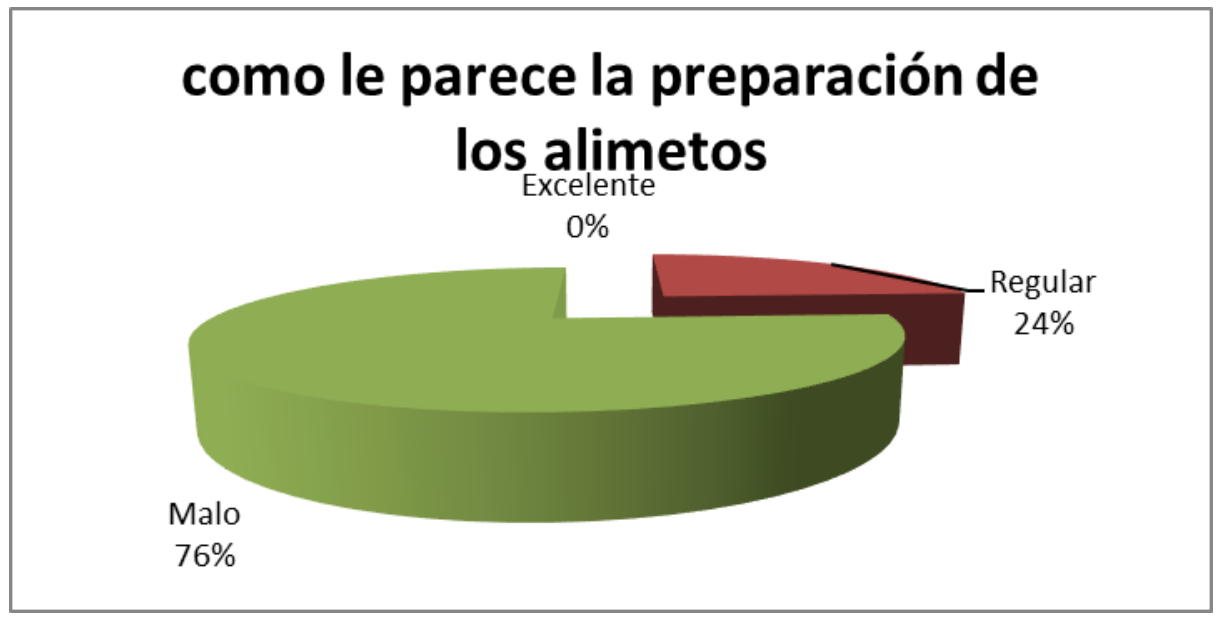

Fuente: Elaboración propia

La grafica refleja como los consumidores de los productos de la organización no satisfacen las expectativas de los mismos; porque el $76 \%$ de los encuestados le parece que la preparación de los alimentos es de mala calidad y el $24 \%$ dice que es regular.

Ilustración 7 Calidad de la proteína

\section{¿como Considera ud. la calidad de la proteina que consume?}

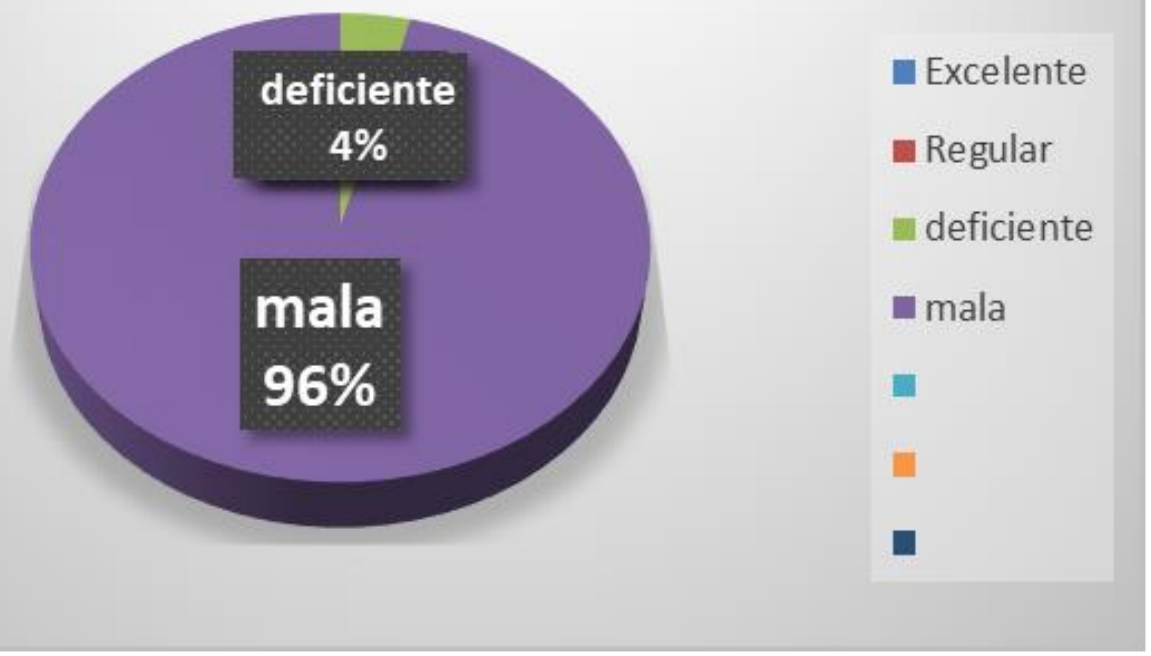

Fuente: Elaboración propia 
En esta ilustración que corresponde a la numero 7, El 96\% de los internos manifiesta que la calidad de la proteína es mala calidad, el restante $4 \%$ dice que la proteína es deficiente.

\section{¿cuales son los insumos que mas se desperdician en la comida que recibe en la Carcel?}

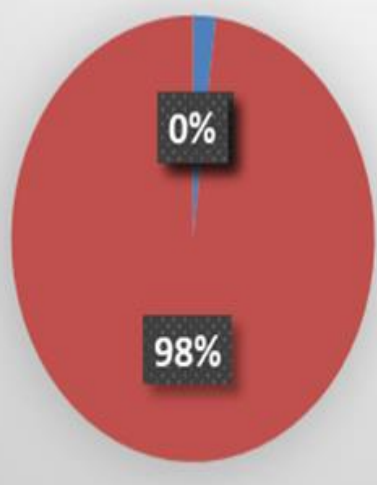

carbohidratos

- proteina

- Otra cual

Fuente: Elaboración propia

A los encuestados se les pregunto por cuáles es el insumo que más se desperdicia en la comida que recibe en la cárcel, la respuesta predominante es la proteína, esto equivale al $98 \%$ de los encuestados. 
Ilustración 9 Como mejorar la alimentación

¿Cómo se puede mejorar el servicio de alimentación que presta proalimentos Liber SAS en la carcel de varones de la ciudad de manizales?

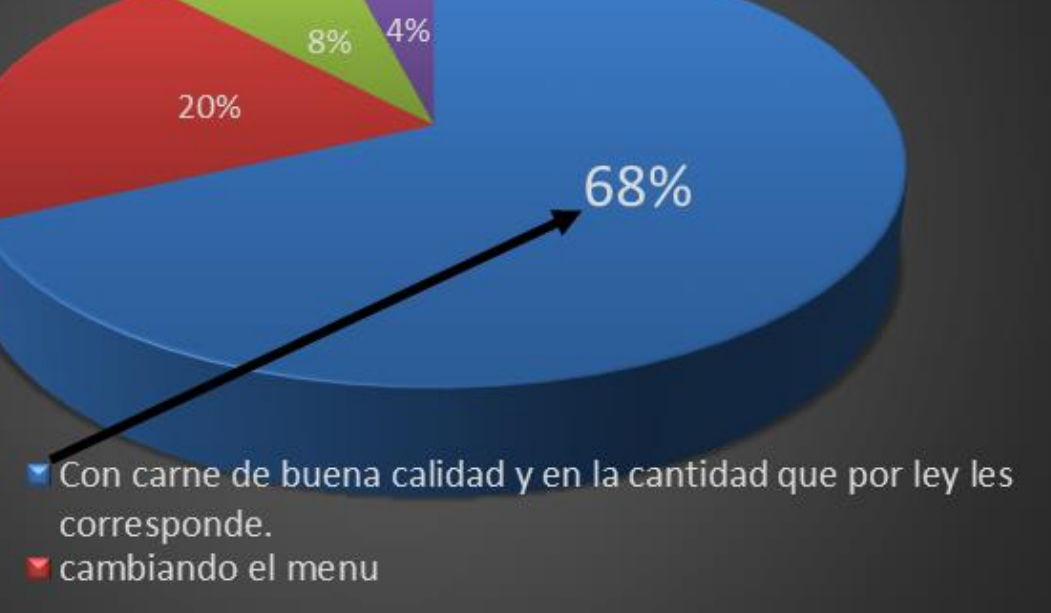

Fuente: Elaboración propia

A la pregunta cómo se puede mejorar el servicio de alimentación que presta Liber SAS en la Cárcel de varones de Manizales, el 68\% de los encuestados manifiestan que se debe servir carne en buen estado y en la cantidad que por ley les corresponde. 


\section{¿Las raciones de proteina que usted recibe son del mismo tamaño todos los dias?}

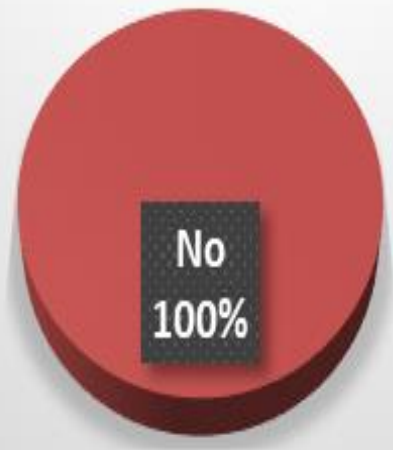

Fuente: Elaboración propia

Sobre la pregunta de si las raciones de proteína que usted recibe son del mismo tamaño todos los días, los encuestados respondieron, no esto significa el $100 \%$ de los encuestados argumentan que el producto que presenta Liber no es uniforme.

Y sobre la pregunta de si le gustaría que las porciones de proteína fueran iguales, el $96 \%$ de los encuestados quieren que se estandaricen los tamaños de las carnes y de esta manera recibir todos la misma cantidad y condiciones. 


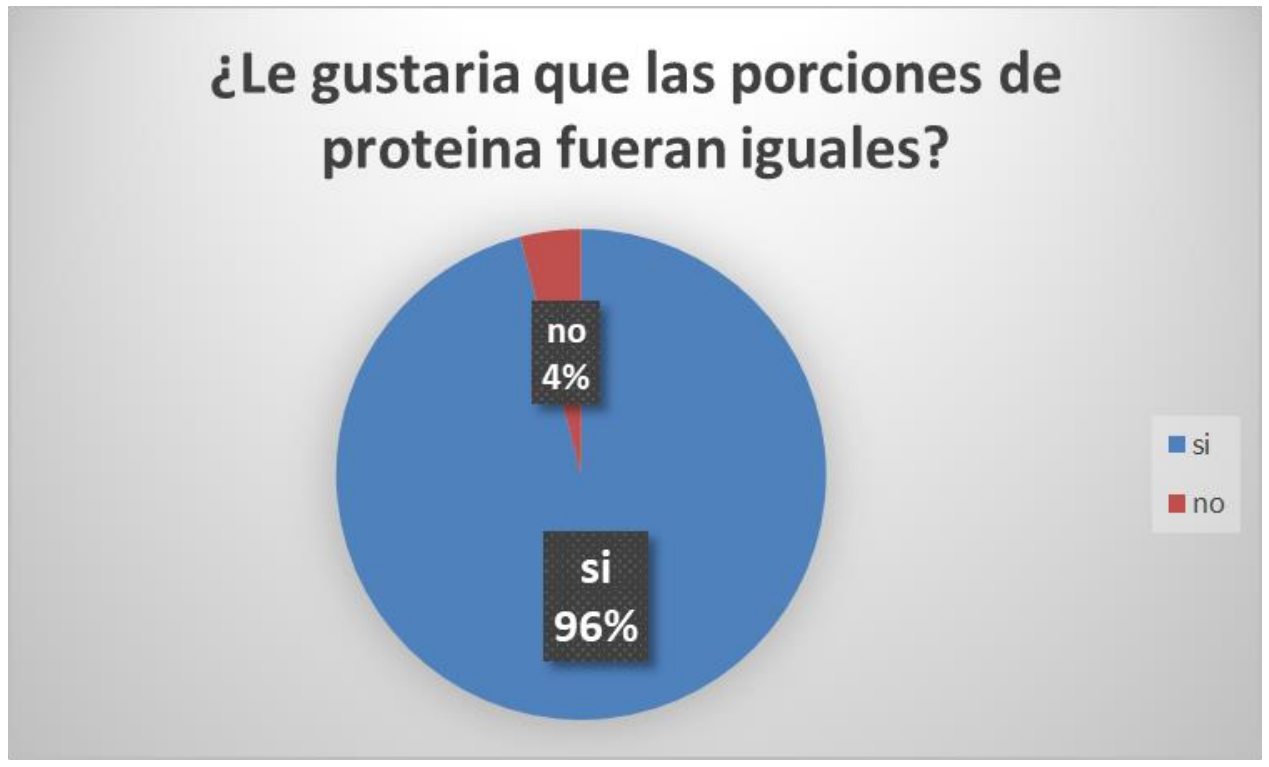

Fuente: Elaboración propia

En la ilustración número 11 se observa que tan solo el $4 \%$ de los encuestados se encuentra a gusto con la proteína que recibe en las raciones diarias; por ende significa que el $96 \%$ de los encuestados está inconforme, no quiere más de lo mismo, siendo para los consumidores una carga más en su trasegar diario.

De lo anterior se puede concluir que el área productiva de Proalimnetos Liber S.A.S. presenta problemas y requieren una solución que disminuya sus costos de producción por perdida de materia prima y que a la vez satisfaga las necesidades de los consumidores Estas son algunas de las bases más sólidas que presenta la investigación para llegar a sugerir a la empresa que si los clientes no están satisfechos, la organización requiere mejorar algunas de sus áreas y en especial el de preparación de alimentos y con un subproceso que utilice herramientas tecnológicas y personal capacitado puede mejorar ostensiblemente la calidad y rentabilidad.

Para producir y distribuir los alimentos con la calidad que merecen los clientes en cuanto a la proteína que requieren consumir, se necesita un 
subproceso dentro del proceso de preparación de alimentos, donde se porcionen y embalen en bolsas plásticas selladas herméticamente, para garantizar la homogeneidad, peso y calidad ofertada en el contrato.

Los cambios que se proponen están enfocados a mejorar la calidad de la producción de alimentos que se brinda a los penados, mediante la inclusión de un subproceso (porcionado), esto se propone como solución de uno de los problemas más relevantes en los procesos operativos de Proalimentos Liber. De esta manera se busca mostrar un enfoque de mejora continua para la organización.

\subsection{Planteamiento y Formulación del Problema a Solucionar}

El enunciado del problema operativo detectado se localiza en el área de producción, hace falta estandarización en los procesos que allí se cumplen, lo que genera malas prácticas de manufacturas, con el resultado final el de consumidores insatisfechos porque el producto que reciben no cumple con las expectativas generadas con el menú que presenta la empresa Liber diariamente. Unas veces la proteína no tiene el peso adecuado o las condiciones fitosanitarias causan quebrantos de salud a los usuarios de estos productos.

La organización hasta el momento no tiene mapa de procesos, haciendo aún más difícil identificar paso a paso los procedimientos que se deben seguir para lograr cumplir con los estándares de calidad en productos terminados. Los costos en que incurre la organización por devoluciones a causas de productos en mal estado alcanzan un 37\%, según las cifras reportadas en el área financiera de la empresa.

Al proceso de preparación de alimentos le hace falta la creación de un subproceso que corrija las fallas presentadas en el manipuleo de las proteínas que requieren de cadena de frio, pues con el método de trabajo utilizado en la actualidad se interrumpe el protocolo y estos insumos pierden sus propiedades y calidad. 
A continuación, se presenta la caracterización del problema productivo de Pro alimentos Líber S.A.S. Este se inicia con la compra de la materia prima (carnes, lácteos, vegétales, granos, tubérculos etc..), posteriormente es transportada en vehículos acondicionados con refrigeración, en la entrada principal de la cárcel son recibidos por carretas que recorren 150 metros hasta el almacén, allí se separan y los cárnicos son enviados a los cuartos fríos, lo demás es guardado en almacén; al siguiente día se interrumpe la cadena de frio con la retirada parcial de la proteína del refrigerador, pues se requiere parte de este para la preparación de los alimentos, con esto se culmina el proceso de manipulación de alimentos y sigue el de la entrega a los clientes Destacando el problema de la interrupción prolongada que se le da a las proteínas fuera del cuarto de frio.

\section{Ilustración 12Mapa de proceso general}

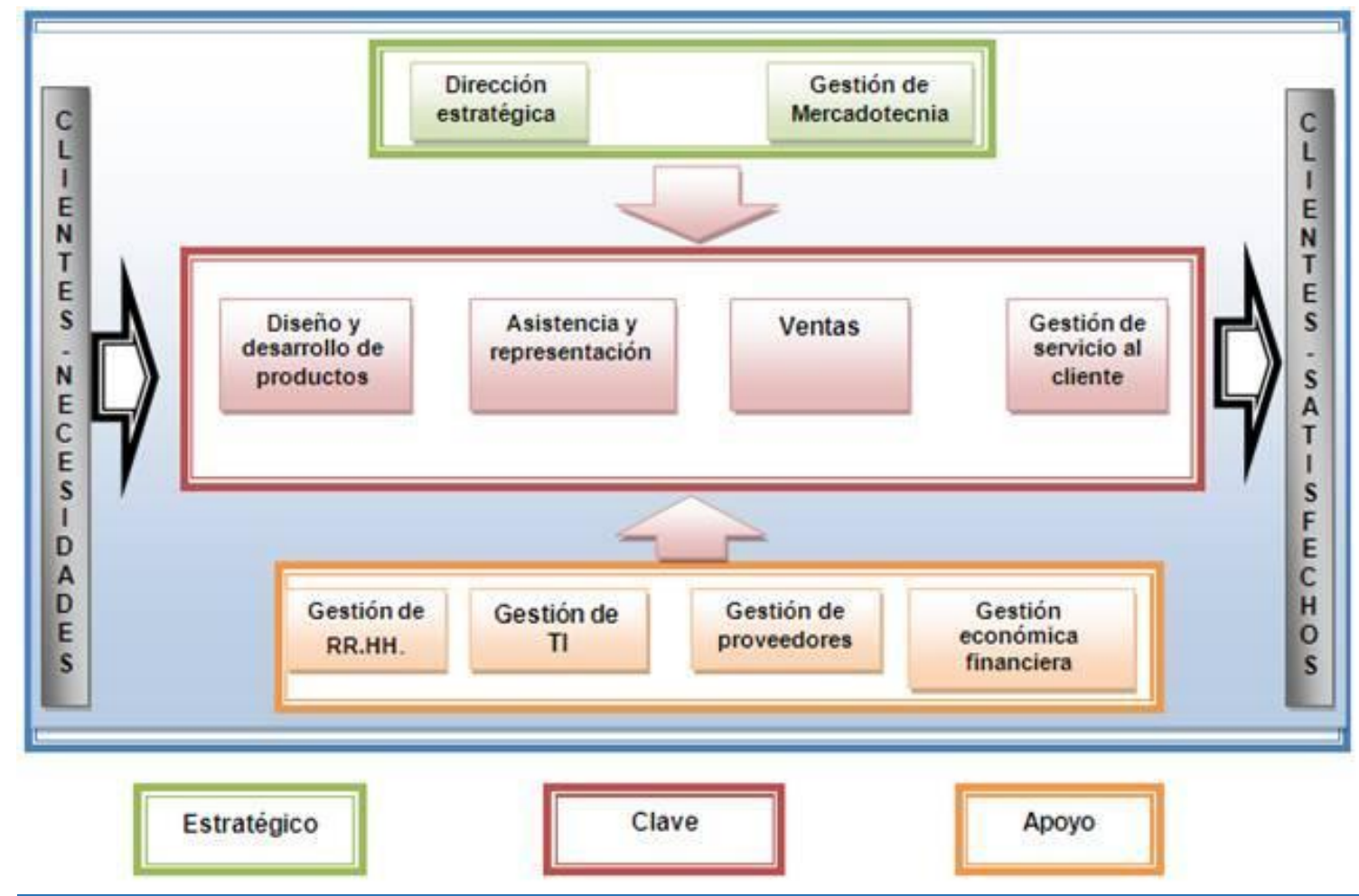

Fuente: Formato mapa proceso

En la ilustración que antecede se observa como todos los procesos convergen en el mismo punto, el del cliente, se inician actividades tratando de suplir la necesidad de los consumidores, la de alimentarse, para esto el proceso 
de diseño y desarrollo de productos elabora un menú bien balanceado, cuenta con un proceso de asistencia y representación en la ciudad de Bogotá; las ventas en proceso licitatorio garantiza por un año la comercialización del producto y la gestión de servicio al cliente con los servicios de nutricionista, de esta manera culmina el proceso operativo. Esta acompañado por los procesos estratégicos manejados por la gerencia y el de apoyo en lo financiero.

Otro de los grandes inconvenientes que afronta la empresa están relacionados con las enfermedades adquiridas por los internos por la ingesta de alimentos en mal estado, "es importante mencionar que durante el 2017, en la Cárcel de Manizales se presentaron 20 brotes de enfermedades transmitidas por alimentos) ETA, estos fueron de etiología diversa, por alimentación suministrada en el establecimiento, elaboración de productos artesanales, baja disponibilidad de agua potable, entre otros; la mayoría causada por los proceso para la producción de alimentos y las dificultades en la tecnificación de estas actividades" (Carcelario, 2017, pág. 1).

El planteamiento del problema se plantea de la siguiente manera:

¿Cómo mejorar el área de producción que permita reducir el desperdicio de materia prima y mejorar la satisfacción del cliente final de la empresa Liber SAS en la Cárcel La Blanca de Manizales -Caldas?.

\subsection{Propuesta de Solución}

La solución al problema de pérdidas de materia prima y la insatisfacción del cliente se presenta mediante un modelo que vincula la relación entre causas y consecuencias del problema, por ende y para llegar a encontrar la mejor alternativa se proponen dos alternativas, con el análisis de impacto tanto positivo como el negativo en la implementación de las mismas explicando el porqué de la decisión 
Los cambios que se proponen están enfocados a mejorar la calidad de la producción de alimentos que se brinda a los penados, mediante la inclusión de un sub proceso que disminuya las perdidas en un $20 \%$ pues esto se puede lograr con trabajo conjunto, capacitación del personal operativo que le permitan estar en una mejora continua..

Según (Chiavenato, 1993, pág. 203) "una estructura organizacional es eficaz cuando facilita a las personas la consecución de los objetivos y es eficiente cuando se consiguen con recursos a costos mínimos", es por ende que la solución debe medir la relación costo beneficio y el estudio de factibilidad dentro de la organización, escogiendo la más conveniente de las propuestas.

Se presenta como alternativa número uno, la creación de un subproceso llamado porcionado que este ligado al proceso de manipulación de alimentos, todo esto laborando en el área operativa; la segunda propuesta está encaminada con el proceso de compra de materia prima donde se maneje un stock de inventarios en cero haciendo que los proveedores entreguen a la empresa "Ios cárnicos "que se requieren para la preparación de alimentos del día a día.

A continuación se presentan dos graficas llamadas árbol de decisiones en los cuales se facilita la labor de escoger la mejor opción para que la empresa disminuya las perdidas y mejore la calidad de los productos. 
Ilustración 13 Árbol de decisiones primera parte

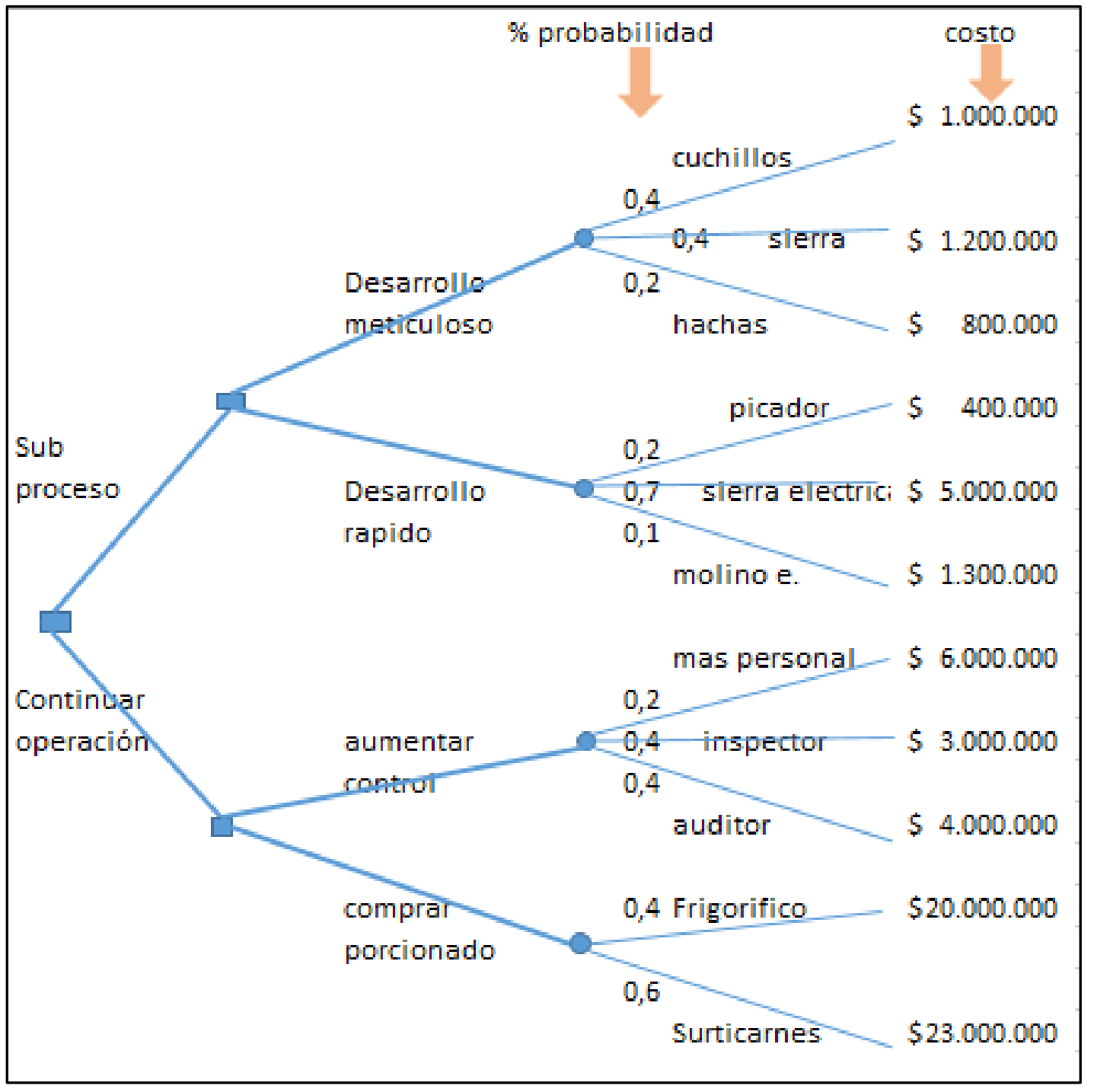

Fuente: Elaboración propia

El árbol muestra dos posibles soluciones, en la parte superior, la creación de un subproceso y en cuadro inferior continuar operación, mejorando. los porcentajes de operatividad. De esta manera la empresa fácilmente puede inclinarse por la mejor decisión, los círculos representan la incertidumbre sobre las posibilidades y hacia la izquierda se muestran los cuadros de decisión; en la derecha está el costo que incurre la organización al implementar dicha alternativa.

Al multiplicar el porcentaje por el costo, se encuentra un valor que ayuda a clarificar porque se busca disminuir costos y aumentar beneficio, resultados que 
se insertan en los nodos o círculos donde están las consecuencias o dudas. Hay ya están listos los datos para calcular el valor que mostrara la mejor decisión.

\section{Ilustración 14 Resultado árbol decisiones}

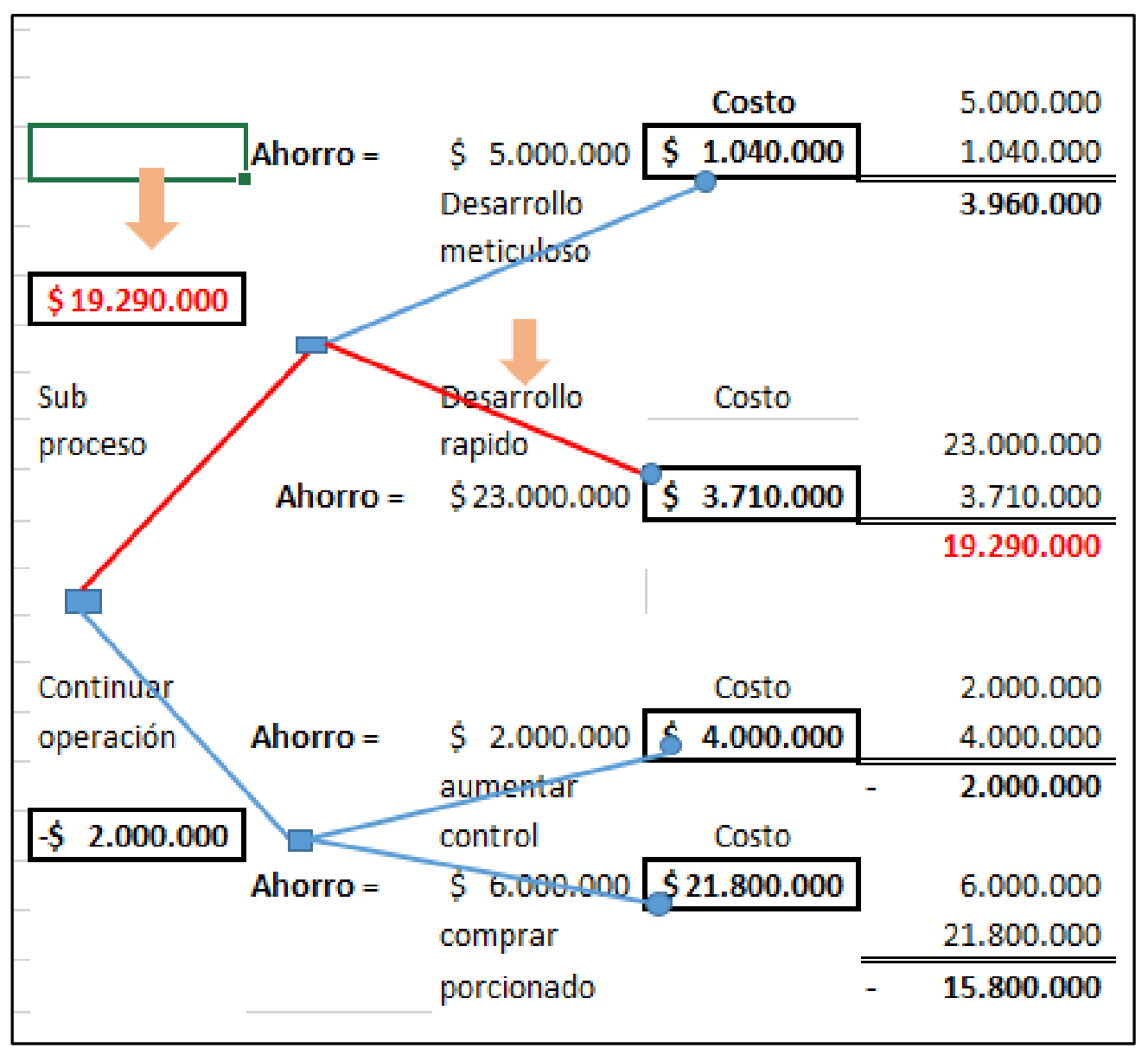

Fuente: Elaboración propia

Para complementar el trabajo realizado en el árbol de decisiones se sigue la línea de color rojo en el sentido derecha - izquierda, está el primer resultado con el menor costo y siguiendo la recta se llega a la mejor decisión que es la creación de un subproceso porque los gastos ocasionados por desperdicios se disminuyen a $\$ 3.710 .000$, lo que es igual al $5 \%$ de los desperdicios y con el procedimiento que normalmente lleva la empresa 
Ilustración 15 Comparativo de opciones

\begin{tabular}{|c|c|c|c|}
\hline & Causas de los problemas & $\begin{array}{l}\text { 1. Creación de subproceso } \\
\text { procionado }\end{array}$ & 2. Compra diaria de carnes \\
\hline 1 & $\begin{array}{l}\text { Deficiencia en la calidad de } \\
\text { los productos }\end{array}$ & $\begin{array}{l}\text { Efecto positivo, se } \\
\text { garantiza la preservación } \\
\text { de las propiedades }\end{array}$ & $\begin{array}{l}\text { Efecto neutro: al inicio mejora la } \\
\text { calidad materia prima pero en la } \\
\text { manipulación puede fallar }\end{array}$ \\
\hline 2 & Costo de producción & $\begin{array}{l}\text { Efecto positivo:Reduce los } \\
\text { costos hasta en } 10 \%\end{array}$ & $\begin{array}{l}\text { Efecto negativo: Aumenta costos } \\
\text { en } 1 \% \text { con pago de fletes y } \\
\text { compra al detal }\end{array}$ \\
\hline & $\begin{array}{l}\text { Deficiencia en los procesos y } \\
\text { procedimientos productivos }\end{array}$ & $\begin{array}{l}\text { efecto positivo: debido a la } \\
\text { estrategia de utilizar } \\
\text { herramietas tecnologiacas }\end{array}$ & $\begin{array}{l}\text { Estrategicamente no es viable } \\
\text { porque relentiliza el proceso en } \\
\text { el area operativa. }\end{array}$ \\
\hline
\end{tabular}

Fuente: Elaboración propia

De acuerdo a lo enunciado se establece que la propuesta de la creación de un subproceso llamado "porcionado" anula las causas del problema y genera por tanto una solución a las mismas. En cambio con la segunda propuesta se observa que no produce ningún efecto sobre las causas y en cambio empeora la situación de las consecuencias de la empresa Liber SAS.

En consecuencia la mejor propuesta que se presenta es la primera con la creación de un subproceso que da respuesta a las necesidades expuestas por los penados en la investigación realizada, es tangible con la reducción de costos. Al porcionar los cárnicos con peso y las condiciones fitosanitarias establecidas en la Ley 65 de 1993 y modificadas por el artículo 5 de la Ley 1709 de 2014, donde se establecen pautas para el manejo adecuado y de una manera digna para las personas en estado de vulnerabilidad (presos).

La mencionada propuesta está acorde a "otras normas que deben implementarse y se armonizan con las anteriores son la Resolución 719 de 2015, por la cual se establece la clasificación de los alimentos para consumo humano de acuerdo con el riesgo en salud pública (40), y el Decreto 60 de 2002 que promueve la aplicación del Sistema de Análisis de Peligros y Puntos de Control Crítico (HACCP) en las fábricas de alimentos y se reglamenta el proceso de certificación (41). Esta última va a asegurar que los procesos cuenten con técnicas limpias para 
alcanzar la inocuidad en la cadena alimentaria". (Bejarano, Jhon Jairo, Carlos Augusto, \& Lilianaa, 2015, pág. 531)

De esta manera se garantiza la factibilidad de la propuesta porque garantiza a la empresa cumplir con los requerimientos legales y de paso puede obtener una certificación en manipulación con el respeto de la cadena de frio y para este caso apoyado la incorporación de la sierra eléctrica, como herramienta de apoyo puede repetir experiencias exitosas como el trabajo realizado en empresas especialistas en este tipo de alimentos como lo es el de la Cooperativa Colanta, "con la distribución de 200 toneladas de carne diaria a todo el país". (Colanta, Logros de colanta, 2017, pág. 2)

Con el objeto de garantizar el éxito de la propuesta se plasma otro ejemplo, el desarrollo de un subproceso en la parte de procesamiento de alimentos, que realiza la empresa "Frisby" que cuenta con amplio respaldo y clientela muy bien definida, se ve reflejada "en la gran crecimiento productivo en la última década" (Frisby, 2007, pág. 1) utiliza demás de la sierra eléctrica, el uso de otras herramientas como la banda trasportadora, con el fin de garantizar la idoneidad en la calidad del producto.

A continuación se muestra cómo quedaría organizado el mapa de procesos en Liber SAS 


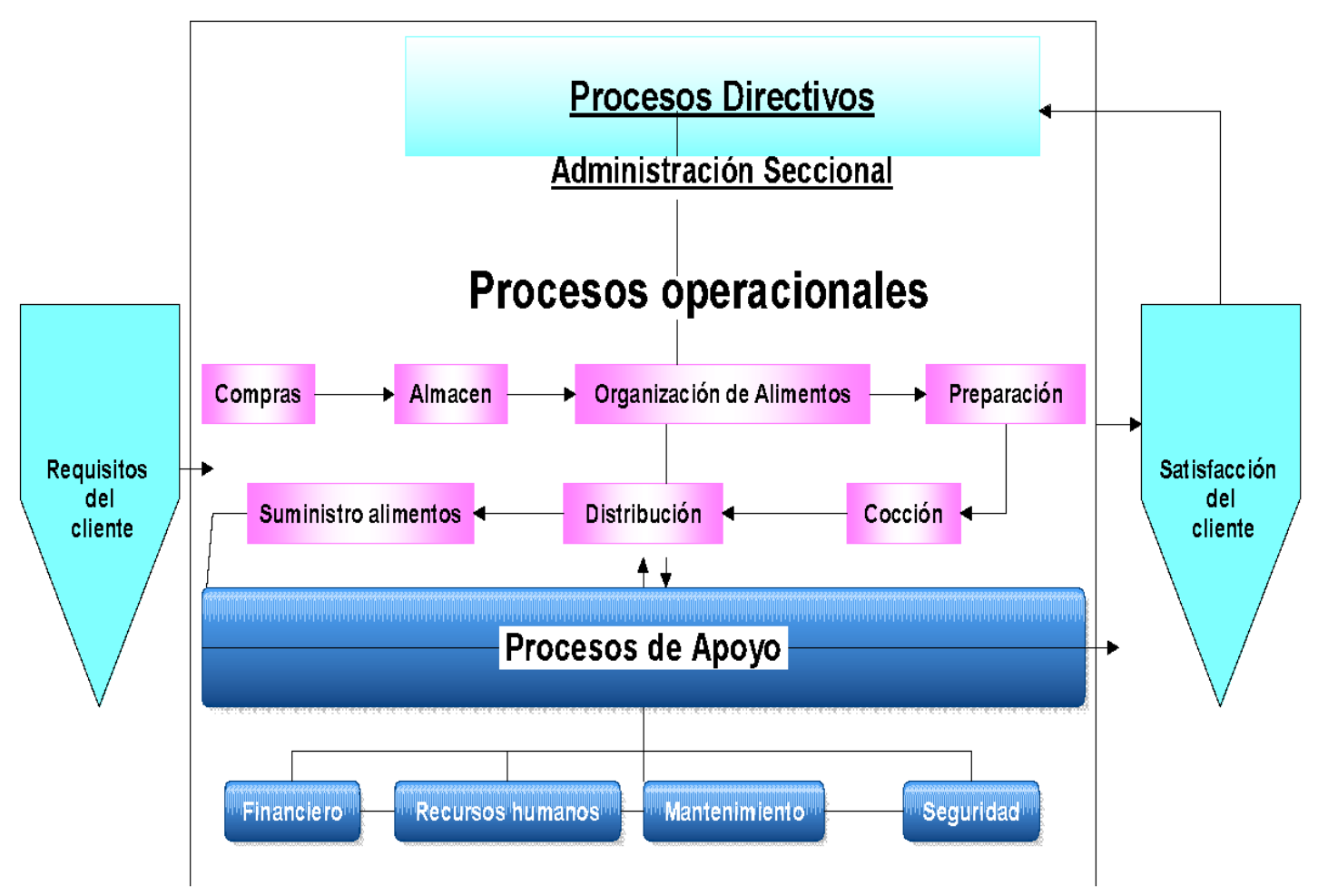

Fuente: Elaboración propia

En esta ilustración se muestra el mapa de proceso de la parte operacional en Liber SAS, Los requisitos del cliente como base para el inicio de actividades, la compra de materia prima, respetando la cadena de frio, el traslado hasta el almacén, la separación de materia prima en la organización de los alimentos, continua la preparación de los mismos con la debida cocción y se inicia el camino para transitar hasta los distintos patios de la cárcel donde son distribuidos y suministrados a los internos del Penal.

Con la creación del subproceso se logra evitar infringir las normas referentes a perecederos "el alimento que, en razón de su composición, características físico-químicas y biológicas, pueda experimentar alteración de diversa naturaleza en un tiempo determinado y que, por lo tanto, exige condiciones especiales de proceso, conservación, almacenamiento, transporte y expendio"3.

\footnotetext{
${ }^{3}$ Decretó 3075 de 1997 expedido por la Presidencia de la republica
} 
Puesto que los cárnicos requieren de un sistema de enfriamiento durante el tiempo que estén guardados esperando su debida cocción.

Para lograr el éxito operativo se espera que la operación este respaldada por la parte financiera, el de recursos humanos, el de mantenimiento para la maquinaria y equipos, culminando con la parte de seguridad de instalaciones.

\section{Ilustración 17 Subproceso porcionado}

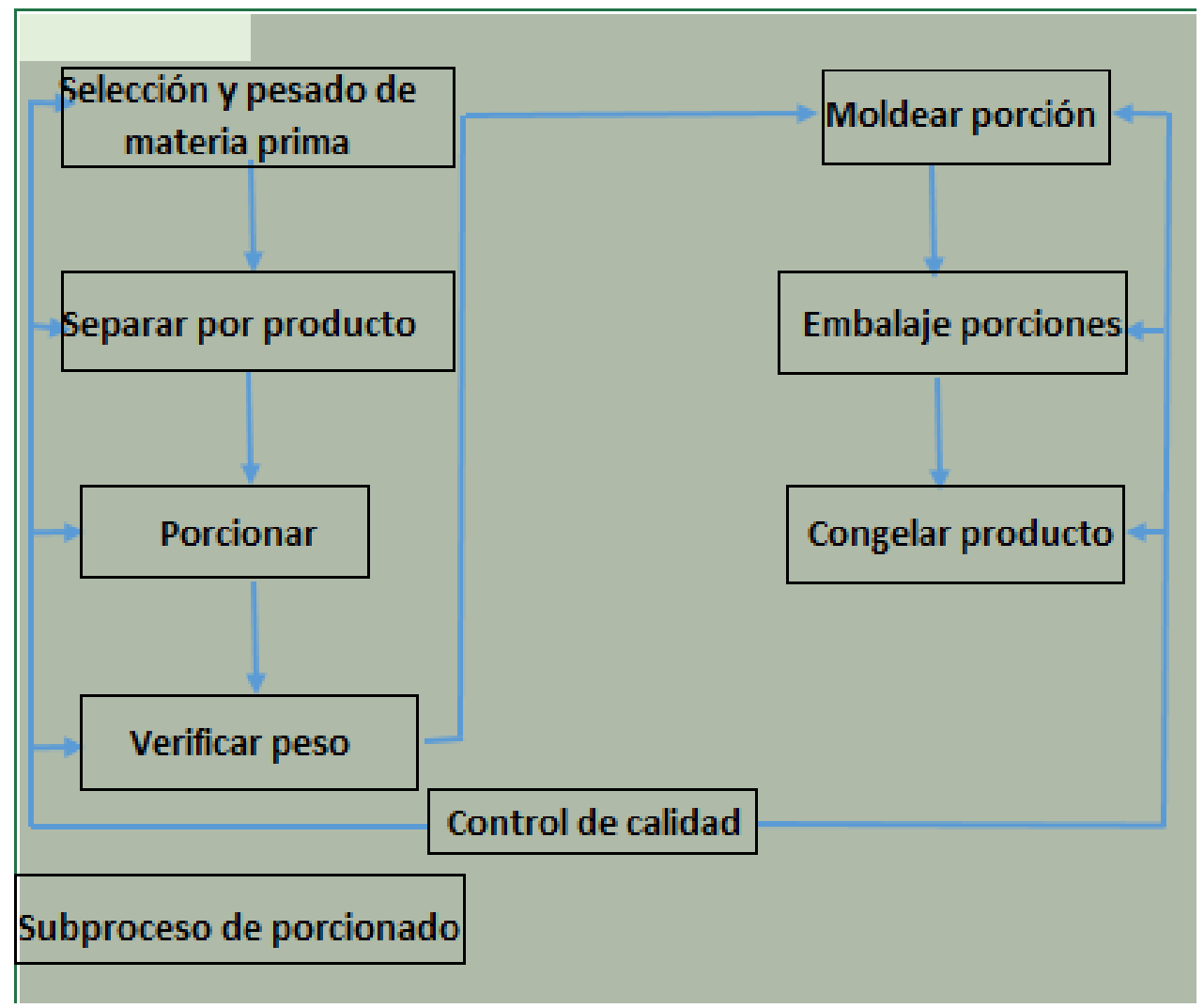

Fuente:Elaboración propia

El subproceso de porcionado es un ciclo tal como se muestra en la anterior ilustración, parte superior izquierda de la pantalla esta la selección y el pesado de la materia prima, luego pasa a la separación por productos, lo que es igual a separar las carnes de acuerdo a su origen; continua con el corte utilizando la Sierra eléctrica en porciones uniformes, en que tiene el origen en la selección y pesado de materia prima, realizado por la sierra eléctrica, hay que verificar peso para continuar luego con moldear la porción de acuerdo al embalaje de la porción. Una vez realizada esta labor debe ser congelado el producto, y en este momento está 
finalizado el subproceso que en todo momento es fiscalizado con un riguroso control de calidad.

La legislación Colombiana en especial el Título V de la Ley 9 de 1979, establece conceptos y define la normatividad sobre sanidad e inocuidad en las buenas prácticas de manufactura en cuanto a la provisión de alimentos. De esta manera se cumple si los alimentos son porcionados y luego almacenados, para posteriormente prepararlos dependiendo las raciones que requieran los consumidores así garantiza que no se interrumpe la cadena de frio de los alimentos que están guardados para los días siguientes.

La empresa Proalimento Liber necesita cumplir con Buenas Prácticas de Manufactura (BPM). "Son los principios básicos y prácticas generales de higiene en la manipulación, preparación, elaboración, envasado, almacenamiento, transporte y distribución de alimentos para consumo humano, con el objeto de garantizar que los productos se fabriquen en condiciones sanitarias adecuadas y se disminuyan los riesgos inherentes a la producción" (Manual de Manipulación de Alimentos, 2014, pág. 3). 


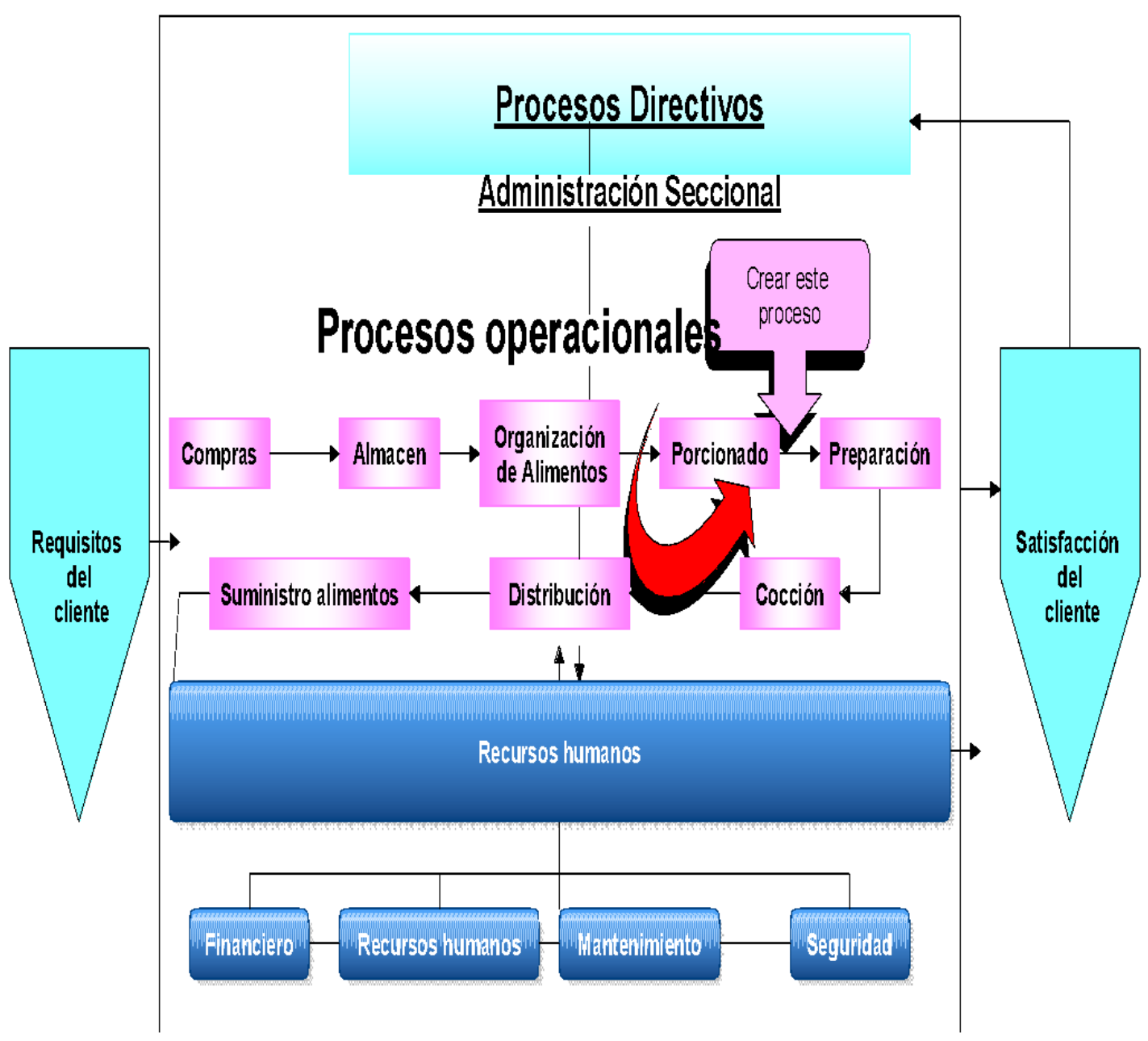

Fuente: Elaboración propia

Como se puede observar en el mapa de procesos, se encuentra resaltado con una flecha de color rojo, la ubicación del subproceso que en el esquema depende del proceso de organización de alimentos, donde se puede mejorar la calidad de los productos y a la vez disminuir los costos que incurre la empresa hasta en un $37 \%$. Para que esta propuesta tenga éxito se necesita la integración de oficinas como Talento Humano y de la gerencia entre otras.

La importancia de incluir el subproceso de porcionado es fundamental para cumplir las Buenas Prácticas de Manufactura (BPM) que son "todas las acciones que se deben realizar para reducir los riesgos microbiológicos, físicos y químicos 
en la producción y benéfico del producto, que permitan la elaboración y producción de alimentos de inocuidad comprobada y de la calidad y desempeño que cumplan con las expectativas de los clientes y consumidores; involucran tanto al personal manipulador como a las instalaciones donde se llevan a cabo los procesos productivos, los equipos y utensilios empleados y la forma como estas actividades han de llevarse a cabo" (Republica, 1997, pág. 17)

La forma como se logre concientizar y capacitar a los operarios y al encargado del control de calidad de como porcionar la proteína de origen animal necesita almacenamiento con refrigeración y hasta congelación, teniendo en cuenta las condiciones cambiantes de temperatura, humedad y circulación del aire que se presentan dentro de las instalaciones de la planta operativa y que es requiera para cada alimento especifico. Así se garantiza el control de temperatura que asegure la conservación de los carnicos.

La creación del proceso de porcionado no es necesario contratar personal adicional por parte de la empresa; los cargos que intervienen en el proceso sugerido (porcionado) son los siguientes:

Ingeniero de Alimentos: Persona que recibe las órdenes directamente de la gerencia y asume los roles de administrador de la empresa en la ciudad. Es el encargado de recibir la materia prima en el hangar, pesar, contar, controlar y ordenar el ingreso a la sección del almacén, donde se crea el proceso de porcionado.

Dietista: Su cargo depende del Ingeniero de alimentos, es la encargada de recibir la materia prima en el almacén, donde ordena a los operarios separar los alimentos en secciones, controlando y vigilando las cantidades que se almacenan. En el nuevo proceso debe pesar las raciones que se tajan de carne, antes de ingresar al enfriador.

Operarios: Personas encargadas de manipular la materia prima, que en el nuevo proceso requieren tajar o porcionar las carnes por raciones, luego empacarlas y finalmente llevarlas al enfriador, donde culmina este nuevo proceso. 
A continuación se muestra la caracterización del proceso operativo que sirve como objeto de práctica según los problemas detectados, de la siguiente manera.

Ilustración 19 Caracterización proceso

\section{Whona: varectevizacion de un proceso}

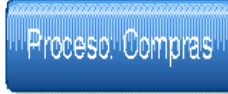

\section{Objetivo: Adquisicion de insumos alimentarios para la alimentacion de personal carcelario de Manizales}

\begin{tabular}{|c|c|c|c|c|}
\hline Proveedores & $\begin{array}{l}\text { Elemento de } \\
\text { entrada }\end{array}$ & $\begin{array}{l}\text { Procedimiento } \\
\text { realizado }\end{array}$ & $\begin{array}{c}\text { Elemento de } \\
\text { salida }\end{array}$ & \\
\hline $\begin{array}{l}\text { Super cam oos de la in } \\
\text { Plaza de mercado. } \\
\text { Mercaldas. }\end{array}$ & $\begin{array}{l}\text { Carne - verfouras } \\
\text { Arroz - Frijol }\end{array}$ & $\begin{array}{l}\text { Compray transpote } \\
\text { hasta hangar de Carel }\end{array}$ & $\begin{array}{l}\text { Came - Verdura - Arroz } \\
\text { frijol - Papa - yuca }\end{array}$ & Hangar \\
\hline Soporte & & Responsable & \multicolumn{2}{|c|}{ Indicadores } \\
\hline $\begin{array}{l}\text { Reoursos ecor } \\
\text { financier }\end{array}$ & $\begin{array}{l}\text { Momicos } \\
0\end{array}$ & Señor Alejandro Pere & Killo & $\begin{array}{l}\text { madida en } \\
\text { nos de peso }\end{array}$ \\
\hline \multicolumn{3}{|c|}{ Documentos asociados } & \multicolumn{2}{|c|}{ Mecanismos de control } \\
\hline \multicolumn{3}{|c|}{$\begin{array}{c}\text { Planilla de } \\
\text { cantidades a comprar }\end{array}$} & \multicolumn{2}{|c|}{$\begin{array}{c}\text { Bacula - Observación - muestreo } \\
\text { aleatorio simple }\end{array}$} \\
\hline \multicolumn{3}{|c|}{ Requisitos } & \multicolumn{2}{|c|}{ Recursos } \\
\hline \multicolumn{3}{|c|}{ Salubridad - calidad - color - textura } & \multicolumn{2}{|c|}{$\begin{array}{c}\text { Dinero - Operarios - Medio de transporte } \\
\text { Equipos de medición }\end{array}$} \\
\hline
\end{tabular}


Este proceso conlleva dos horas adicionales de trabajo por parte de los operarios, pero una disminución en los costos de $20 \%$, como consecuencia del cuidado de los alimentos que siempre están protegidos en el cuarto frio y solo son sacados para ser cocidos en el siguiente proceso.

\section{"Ficha: caracterización de un proceso}

\section{Proceso: Organizacion alimentos"}

\section{Objetivo: Separar los alimentos en perecederos y no perecederos}

\begin{tabular}{|c|c|c|c|c|}
\hline Proveedores & $\begin{array}{l}\text { Elemento de } \\
\text { entrada }\end{array}$ & $\begin{array}{l}\text { Procedimiento } \\
\text { realizado }\end{array}$ & $\begin{array}{c}\text { Elemento de } \\
\text { salisa }\end{array}$ & Clientes \\
\hline Hangar & $\begin{array}{l}\text { Carne- verduras } \\
\text { arroz-frijol }\end{array}$ & $\begin{array}{c}\text { Transporte hasta } \\
\text { bodega }\end{array}$ & $\begin{array}{l}\text { Came - verduras } \\
\text { arroz-frijol }\end{array}$ & Bodega \\
\hline \multicolumn{2}{|c|}{ Soporte } & \multicolumn{2}{|l|}{ Responsable } & adores \\
\hline \multicolumn{2}{|c|}{$\begin{array}{l}\text { Recursos economicos } \\
\text { financiero }\end{array}$} & Senora Diana Pere & & $\begin{array}{l}\text { medida en } \\
\text { nos de peso }\end{array}$ \\
\hline \multicolumn{3}{|c|}{ Documentos asociados } & \multicolumn{2}{|c|}{ Mecanismos de control } \\
\hline \multicolumn{3}{|c|}{ Planilla de control } & \multicolumn{2}{|c|}{ Observación y conteo por unidades } \\
\hline \multicolumn{3}{|c|}{ Requisitos } & \multicolumn{2}{|c|}{ Recursos } \\
\hline \multicolumn{3}{|c|}{ Perecedero - no perecedero } & \multicolumn{2}{|c|}{$\begin{array}{c}\text { Dinero - Operarios - Medio de transporte } \\
\text { Equipos de medición }\end{array}$} \\
\hline
\end{tabular}


Así se describen las dos propuestas lógicas fundamentadas en consolidar el procedimiento de elaboración de alimentos como hasta el momento la empresa lo ha desarrollado o la propuesta innovadora que consiste en crear un nuevo subproceso para trabajar el porcionado.

Organización del producto: En cuanto a la opción de crear un subproceso denominado porcionado con el objetivo de tajar los alimentos por raciones y estas a su vez en dietas, respetando en todo momento la cadena de frio, este proceso se puede realizar de dos maneras trabajando detalladamente con etiquetas en las carmes o de manera rápida dejando los alimentos en secciones.

Nuevo proceso

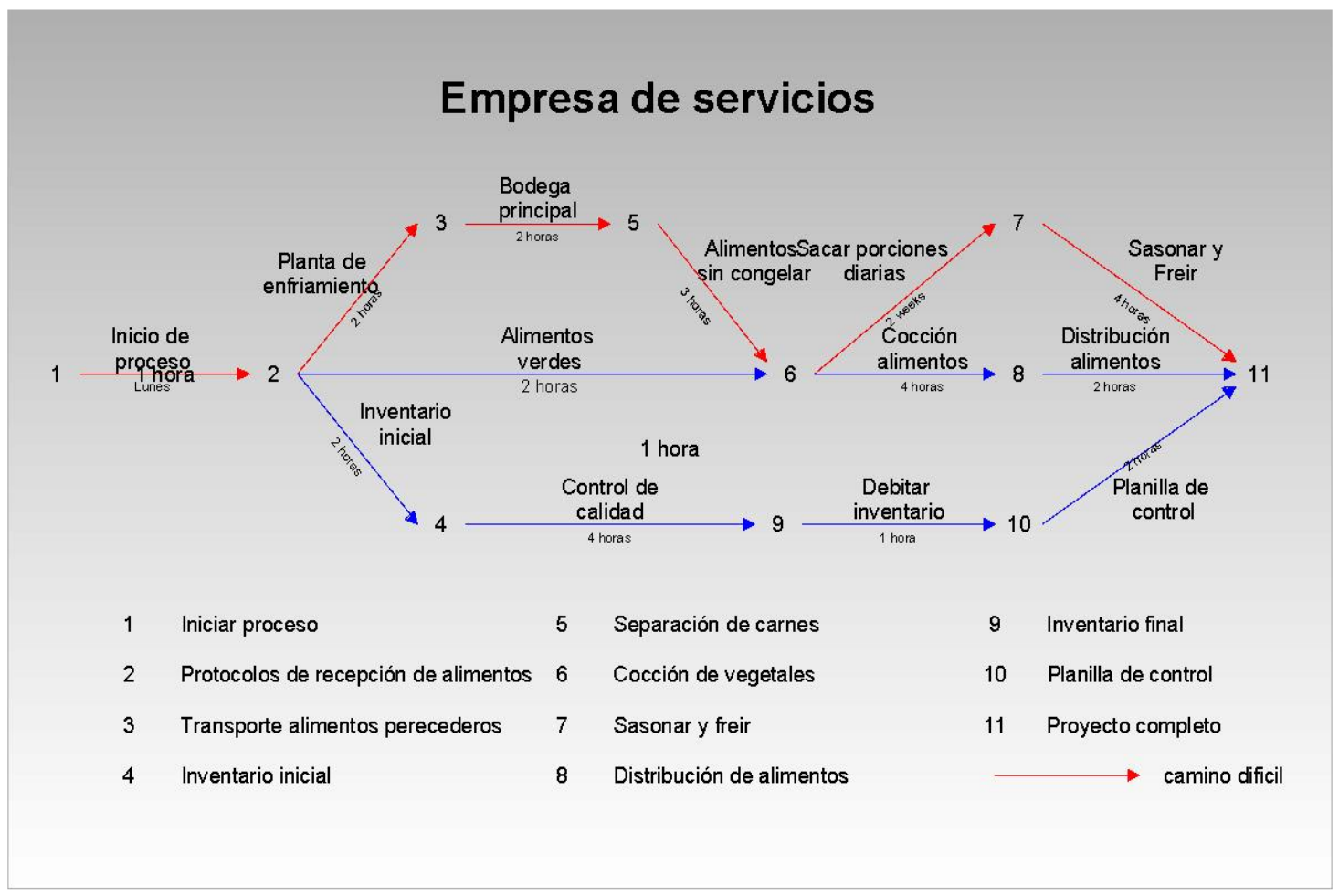

Fuente: Elaboración propia

El proceso de porcionado requiere circular por el camino crítico o difícil pues conlleva realizar dos actividades adicionales antes de pasar al siguiente proceso, como se observa en los nodos 3 y 5 donde se labora en el cuarto frío que requiere 
dos horas adicionales de trabajo antes de continuar con el proceso de enfriamiento o pasar al proceso siguiente que es el de cocción de alimentos.

La transición hacia el nuevo modelo organizacional basado en procesos es compleja y, en general, es aconsejable que sea realizada en etapas. Como hemos señalado, la transición se plantea del viejo modelo tradicional jerárquico por normas a uno horizontal por objetivos y resultados

Se inician las actividades en el proceso de Almacén donde llegan todos los productos del proceso anterior que es el del hangar de recepción de alimentos. Con el fin de crear un nuevo subproceso que se denomina Porcionado se muestran los tiempos de ejecución de cada una de las actividades y se incluye el trayecto por donde normalmente se están realizando los procesos de la empresa.

Para entender mejor a las relaciones de precedencia se utilizan los nodos dentro de una red que "el dibujo de la red de un proyecto suele requerir cierto tiempo y experiencia cuando dibujamos la red de un apoyo por primera vez, no es extraño que coloquemos nuestros nodos (actividades) en la red de tal forma que las flechas (relaciones de precedencia) no son líneas rectas." (RENDER, 2007, pág. 82).

A continuación se presenta la tabla número uno, donde se encuentra como se ordenan las actividades desde el momento en que se planean hasta finalizar las diligencias con la puesta en marcha de todo el proceso, con especial atención en actividades como la de capacitar el personal que no se puede ejecutar hasta tanto no haya culminado el proceso de planeación y el alistamiento de la planta física. 


\begin{tabular}{|c|c|c|c|}
\hline ACTIVIDAD & OBBETINO & TIEMPO & $\begin{array}{l}\text { REELACIONES DE } \\
\text { PRECEDENCIA }\end{array}$ \\
\hline A & Reuniones con directivas & 1 semana & Ninguna \\
\hline B & Organización de espacios físicos & Zsemanas & Actividad1 \\
\hline c & Determinación de personal para el proceso & 1 semana & Actividad 1 \\
\hline D & Capacitación de personal del nuevo proceso & Zsemanas & Actividad 1 de laactividad 3 \\
\hline E & Practicas del personal en el proceso & 1semana & Actividad 1,2,3,4 \\
\hline F & Implementación del proceso & 3semanas & Actividad 1,2,3,4y5 \\
\hline
\end{tabular}

Fuente: Elaboración propia

La implementación del proceso de porcionero se realiza en seis actividades donde el tiempo más óptimo puede tardar nueve semanas y en el tiempo crítico puede demorar 12 semanas, el proceso de implementación del proceso requiere que las cinco actividades anteriores estén culminadas. 


\section{Ejecución del proyecto}

\section{Stock}

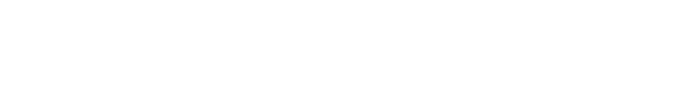

El sistema requiere separar las carnes sin que pierdan propiedades en la cadena de frio.

Tiempo estimado dos horas.

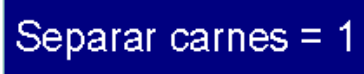

Porcionar

Porcionar o congelar?

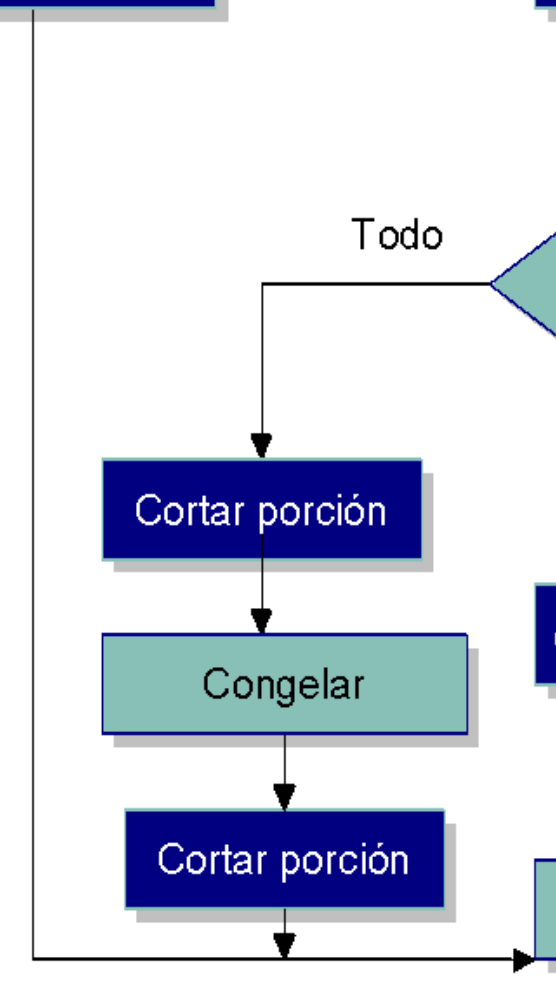

Final del proceso para pasar al siguiente proceso el de cocción.

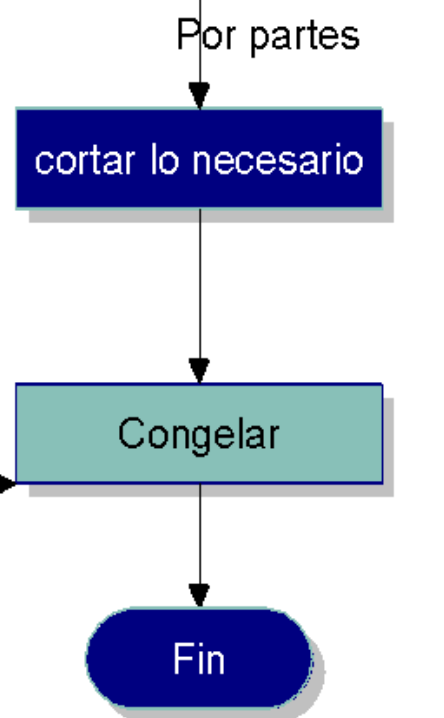

Fuente: Elaboración propia 
Como regla general se aplica el concepto de "antes de que se pueda iniciar una actividad, todas sus actividades predecesoras inmediatas deben haber terminado". (RENDER, 2007, pág. 85). Mostrando las siguientes características:

- Si una actividad sólo tiene una predecesora inmediata, su IMTE es igual al FMTE de su predecesora.

- Si una actividad tiene múltiples predecesoras inmediatas, su IMTE es el máximo de los valores FMTE de sus predecesoras. Inicio Más Temprano $=($ IMTE $)$ Final Más Temprano $=($ FMTE $)$

- $\quad$ Inicio Mas Tardío $=($ IMTA $)$ Final Más Tardío $=($ FMTA $)$

- $\mathrm{HOLGURA}=($ IMTA - IMTE $) \quad$ CRITICO = es 0 sin HOLGURA

- $\quad$ IMTE = Max. (FMTE de todas las predecesoras inmediatas)

Como se necesita saber el FMTE (final más temprano) de una actividad, se estima de la suma de su instante de inicio más temprano más el tiempo de su duración con la siguiente fórmula:

- $\mathrm{FMTE}=$ IMTE + Duración de la actividad.

Para el caso de los tiempos más tardíos se requiere primero conocer "de que antes de que se pueda iniciar una actividad se deben haber terminado todas las predecesoras inmediatas." (RENDER, 2007, pág. 87). Con las siguientes reglas:

- Si una actividad es predecesora inmediata de solo una actividad, si FMTA es igual al IMTA de la actividad que la sigue de inmediato. 
Tabla 2 Estudio de tiempos de actividades

\begin{tabular}{|c|c|c|c|c|c|c|c|}
\hline Actividad & $\begin{array}{l}\text { Inicio Mas } \\
\text { Temprano } \\
\text { (IMTE) }\end{array}$ & $\begin{array}{l}\text { Final Mas } \\
\text { Temprano } \\
\text { (FMTE) }\end{array}$ & $\begin{array}{l}\text { Inicio Mas } \\
\text { Tardio } \\
\text { (IMTA) }\end{array}$ & $\begin{array}{l}\text { Finalmas } \\
\text { Tardio } \\
\text { (FMTA }\end{array}$ & $\begin{array}{l}\text { HOLGURA = } \\
\text { (IMTA- } \\
\text { (MTE) }\end{array}$ & CRITICO & $\begin{array}{l}\text { HOLGURA } \\
\text { FMTA-FMTE }\end{array}$ \\
\hline A & 0 & 1 & 0 & 1 & 0 & SI & 0 \\
\hline$B$ & 2 & 2 & 2 & 3 & 0 & SI & 1 \\
\hline$C$ & 3 & 3 & 4 & 4 & 1 & SI & 1 \\
\hline 0 & 4 & 5 & 5 & 6 & 1 & NO & 1 \\
\hline$E$ & 7 & 7 & 7 & 8 & 0 & SI & 1 \\
\hline $\mathrm{F}$ & $g$ & 10 & $g$ & 10 & 0 & SI & 0 \\
\hline
\end{tabular}

Fuente: Elaboración propia

Holgura = IMTA - IMTE u FMTA - FMTE. Holgura igual a una semana; esta actividad es la $\mathrm{D}$ o sea la de capacitación del personal. A continuación se muestra con una línea roja el camino pesimista con cuatro procedimientos que el proceso de porciones se realiza mediante seis actividades que en el tiempo más óptimo puede tardar siete semanas y en el tiempo crítico puede demorar nueve semanas, el proceso de implementación del proceso requiere que las cinco actividades anteriores estén culminadas. Los símbolos que se muestran son para entender la tabla número 2 así 


\section{Tabla 3 Plano de control actividades}

Control del proyecto

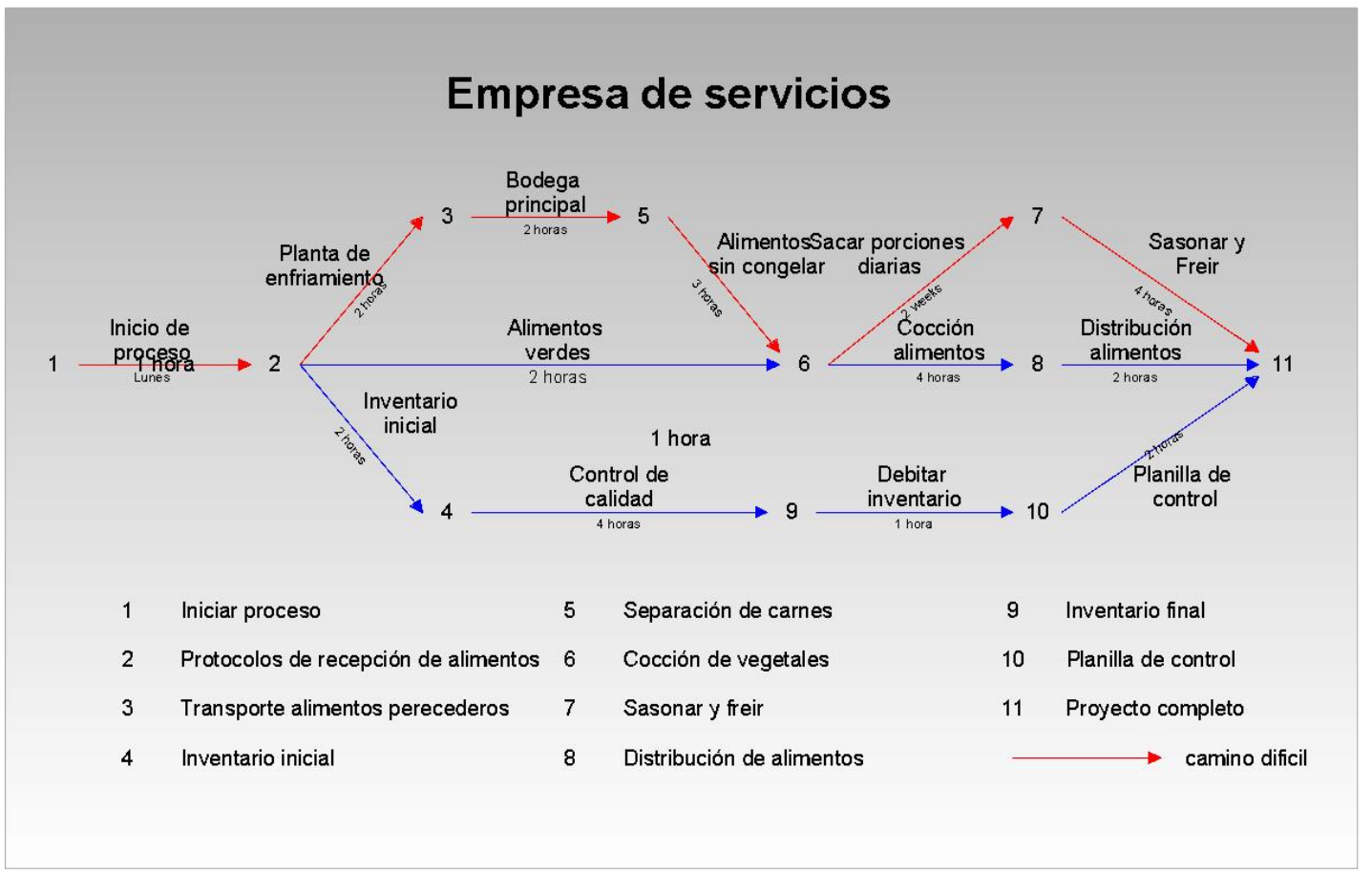

Fuente: Elaboración propia

"Las actividades sin tiempo de holgura se denominan actividades críticas y se dice que están en el camino crítico. El camino critico es un camino continuo en la red del proyecto." (RENDER, 2007, pág. 89) Se muestra el ejemplo de la siguiente manera tomado como base el ejemplo de la red $A O N$, así:

Para iniciar el proceso de porcionado es necesario que la empresa incurra en unos costos aproximados a los $\$ 800.000$, a fin de capacitar a las personas que laboran en el área de manipulación de alimentos y la compra de maquinaria como lo es la adquisición de una sierra eléctrica; con ella los alimentos perecederos, tajándolos en porciones, sin 


\subsection{Marco Referencial}

Para conocer el tema de procesos dentro de la organización es necesario saber el significado y la importancia de los mismos, (Zaratiegui, 1999, pág. 86) "La empresa relaciona los procesos en secuencias ordenadas, agrupadas alrededor de los procesos prioritarios. Estos procesos prioritarios requerirán el concurso de procesos secundarios realizados de forma eficiente para desarrollarse con un alto nivel de rendimiento". Por consiguiente se necesita iniciar con la creación del mapa de procesos de forma que ilustre los pasos a seguir dentro de la empresa.

Las organizaciones necesitan trabajar en procesos con técnicas especializadas que les permitan ser más competitivas por eso en esta investigación aplica la teoría científica donde "la mayor prosperidad no puede existir más que como resultado de la mayor productividad posible de los hombres y de las máquinas del establecimiento: es decir, cuando cada hombre y cada máquina está donde están dando, el rendimiento más grande posible, debido a que, a menos que los hombres y máquinas de usted estén trabajando dando más trabajo diario que los demás hombres y máquinas de alrededor suyo" (TAYLOR, 1911, pág. 21)

Esta teoría propone a las empresas cambios importantes que las hacen ser más competitivas y productivas por ejemplo con respecto a Liber SAS, necesita racionalizar el trabajo tal como lo explica Taylor con la estandarización de los productos "Uniformizar los procesos" con esto se garantiza que todos los comestibles en especial las raciones de carne tengan las mismas características y propiedades, de esta manera se simplifica el trabajo.

La empresa Liber S.A.S., requiere cumplir con lineamientos legales, "Los equipos deben estar instalados y ubicados según la secuencia lógica del proceso tecnológico, desde la recepción de las materias primas y demás ingredientes, hasta el envasado y embalaje del producto terminado." (Gaviria Uribe, 2013, pág. 10) . Lo anterior se encuentra estipulado en el artículo 10 de la resolución 2674 expedido por el Ministerio de Salud. 
La creación de un subproceso implica el estudio de Tiempos y movimientos, con el objeto de capacitar y escoger o seleccionar el personal que tenga las mejores cualidades para el manejo de la nueva maquinaria es decir la sierra para cortar las carnes en porciones individuales. Taylor es un precursor de la selección de personal, en el contenido solo nos referiremos al de preparar a los trabajadores para labora en el nuevo subproceso.

De acuerdo con (Choo, 2000, pág. 322) "la sociedad actual, caracterizada por la producción intensiva, uno de los problemas centrales en la administración de las organizaciones consiste no tanto en crear conocimiento como en crear una visión de conocimiento que defina un mapa mental de la compañía que se quiere construir" sobre este punto Bernal (2010) habla de definir el tipo de conocimiento que es necesario buscar o tal vez mejor crear, con el objeto de ser estratégicos y bastante competitivos en el ámbito global.

En términos generales los autores consultados comparten la idea de estar trabajando en procesos, estudiando falencias, para buscar soluciones y mejorar el conocimiento de sus procedimientos internos buscando especializar cada una de las fases o subprocesos, porque esto tarde o temprano será el termómetro que le indique a Liber su capacidad de competir en el mercado cambiante.

Uno de los ejes centrales de la presente investigación radica en buscar una alternativa que mejore los procesos productivos de la organización y de paso satisfaga las necesidades de los consumidores en este caso los internos del Penal, sin que esto represente un costo adicional para la empresa, sobre esto, "El análisis del consumidor tiene por objeto caracterizar a los consumidores actuales y potenciales, identificando sus preferencias, hábitos de consumo, motivaciones, etcétera, para obtener un perfil sobre el cual pueda basarse la estrategia comercial” (Sapag, Sapag, \& Sapag, 2014, pág. 30).

Para consolidar el subproceso de porcionado es necesario incorporar parte de la Teoría clásica, que va de lo general a lo particular, de arriba hacia abajo y su principal exponente Henry Fayol, donde aplica los elementos de la administración: 
Planeación - Organización - Dirección - Coordinación - Control, haciendo énfasis en la planeación que es "hagamos las cosas de manera científica. Preparando todos los recursos para el proceso de producción", esto es importante porque si la parte estratégica de la empresa no se integra y planifica cada uno de los elementos que se necesitan para lograr este objetivo la investigación pasa a un segundo plano quedando relegada a material de estudio simplemente.

Es posible modificar los procedimientos que realiza la empresa Proalimentos Liber, como lo expresa (TAYLOR, 1911, pág. 322) "cambiar los procedimientos a ojo de buen cubero por sistemas científicos, incluso en los detalles más pequeños, por lo tanto, el enorme aumento de rendimiento que se pueden lograr eliminando movimientos innecesarios y sustituyendo los movimientos lentos e ineficientes por otros movimientos rápidos, ejecutados por los operarios que trabajan en cualquiera de nuestros oficios, puede comprenderse solamente después que se han visto personalmente las mejoras"

El subproceso de porciones de los cárnicos pretende vincular al personal operativo de la empresa Liber con el medio de control y respecto de la inocuidad de los alimentos "es la garantía de que los alimentos no causaran daño al consumidor cuando se preparen y consuman de acuerdo con el uso al que se destina”. (Social, 2013, pág. 2) , pues esto genera la garantía necesaria de que los alimentos al momento de servirlos al cliente consumidor están en las condiciones idóneas para el consumo humano, el manejo y control de la materia prima exigen nuevas y portátiles herramientas para su manipulación.

Las herramientas en este caso están enfocadas en el uso de sierras eléctricas portatiles, para el corte de las porciones y y la banda transportadora manera como se está movilizando los cárnicos por la. Esto ofrece una oportunidad de disminuir las perdidas en un $37 \%$ y aumentar la satisfacción del cliente, aunando esfuerzos de capacitación en el manejo de este tipo de elementos, "las empresas deben tener un plan de capacitación continuo y permanente para el personal manipulador de alimentos desde el momento de su contratación y luego ser reforzado mediante charlas, cursos u otros medios efectivos de actualización. 
Dicho plan debe ser por lo menos 10 horas anuales, sobre asuntos específicos de que trata la presente resolución"4 .

Dicho de otra manera para la creación de

I subproceso no se requiere invertir dinero extra en capacitación pues las leyes como está consagrado en el artículo 13 del decreto 2675 así lo exigen o sea que es cuestión de concatenar y organizar este tipo de instrucción hacia el nuevo procedimiento, ajustando los protocolos compatibles que permitan la ejecución catedrática. Es necesario la implementación de los instrumentos mencionados anteriormente, de esta manera se puede ajustar la caracterización del mapa de procesos al proyecto de la creación de un subproceso, para lograr la aceptación de los trabajadores, pues se mejoran las expectativas de éxito a la empresa.

La cadena de frio se debe respetar en todo momento y al respecto el articulo 126 del decreto ley 019 de 2012, expedido por la Presidencia de la republica indica "Las materias primas conservadas por congelación que requieren ser descongeladas previo al uso, deben descongelarse a una velocidad controlada para evitar el desarrollo de microorganismos y no podrán ser re congeladas. " es decir que el subproceso de porcionado garantiza el corte de las proteínas de origen animal sin necesidad de descongelar y pueden seguir guardadas en el cuarto frio.

En síntesis, la creación de un subproceso necesita "capacitación en el puesto de trabajo que incluya la rotación de puestos, los programas para aprendices, los programas para capacitar al personal suplente y los programas de tutoría formales. Las compañías estadounidenses utilizan cada vez más frecuencia de rotación de puestos" (Robbins \& Judge, 2017, pág. 112), por ende para mejorar el procedimiento se requiere a la vez capacitar a los operarios.

\subsection{Plan de Acción}

\footnotetext{
${ }^{4}$ Articulo 13 del decreto 2674 de 2013, Ministerio de Salud
} 
Este plan se inicia de conformidad con los resultados obtenidos en el diagnóstico inicial, donde se logró dilucidar que en los procesos que se llevan a cabo en el área productiva de la empresa Proalimentos Liber S.A.S., existe una falencia en la manipulación de los cárnicos y es necesario la creación de un subproceso que mitigue los costos de producción y a la vez mejore la calidad del producto ofertado por la empresa.

Se da inicio a la elaboración del plan de acción para mejorar la problemática que se presenta en los procesos productivos de Liber, principalmente en la manipulación de alimentos, tomando como referencia los resultados arrojados por el árbol de decisiones en el diagnóstico inicial, donde también aparecen los resultados de las encuestas realizadas a los internos consumidores, el de costos de producción registrados en el balance general de la empresa del segundo semestre de 2017.

Las acciones pertinentes, para mejorar la producción por procesos, cuentan con la ayuda de la herramienta de gestión $5 \mathrm{~W} 2 \mathrm{H}$ que por sus siglas en ingles indican What? (¿Qué?), When? (¿Cuándo?), Who? (¿Quién?), Where? (¿Dónde?), Why? (¿Por qué?), How? (¿Cómo?), How much? (¿Cuánto cuesta?), junto con los lineamientos exigidos por el gobierno nacional a travez de la resolución 2674 de 2013, Expedia por el Ministerio de Salud que establece las pautas para el correcto manejo, preparación y embalaje de los alimentos, en el artículo 126 del Decreto Ley 019 de 2012, "los alimentos que se fabriquen, envasen o importen para su comercialización en el territorio nacional, requerirán de notificación sanitaria, permiso sanitario o registro sanitario, según el riesgo de estos productos en salud pública, de conformidad con la reglamentación que expida el Ministerio de Salud y Protección Social” (Salud, 2013, pág. 1). 


\section{Ilustración 22Plan de acción}

\begin{tabular}{|c|c|c|c|c|c|c|}
\hline \multicolumn{7}{|c|}{ Subproceso de porcionado } \\
\hline $\begin{array}{c}\text { ¿Qué se debe } \\
\text { hacer? }\end{array}$ & ¿Por qué se hace? & Como se hace? & $\begin{array}{l}\text { ¿Quién lo } \\
\text { hace? }\end{array}$ & $\begin{array}{c}\text { ¿Dónde se } \\
\text { hace? }\end{array}$ & $\begin{array}{c}\text { ¿Cuándo se debe } \\
\text { hacer? }\end{array}$ & $\begin{array}{c}\text { ¿Cuánto va a } \\
\text { costar? }\end{array}$ \\
\hline $\begin{array}{l}\text { La higiene en el } \\
\text { almacenamiento } \\
\text { manipulación, } \\
\text { preparación, } \\
\text { elaboración, } \\
\text { envasado, son } \\
\text { idoneos. }\end{array}$ & $\begin{array}{l}\text { Prevención de } \\
\text { contaminación de } \\
\text { los alimentos por } \\
\text { sustancias toxicas o } \\
\text { microorganismos }\end{array}$ & $\begin{array}{l}\text { mantener los } \\
\text { carnicos con la } \\
\text { misma } \\
\text { temperatura } \\
\text { durante el } \\
\text { proceso }\end{array}$ & $\begin{array}{l}\text { Coordinación } \\
\text { del proyectoy } \\
\text { el Ingeniero de } \\
\text { alimentos }\end{array}$ & $\begin{array}{l}\text { Area de } \\
\text { producción }\end{array}$ & $\begin{array}{l}\text { Durante el } \\
\text { transcurso de } \\
\text { implementación } \\
\text { del subproceso }\end{array}$ & $\begin{array}{l}\$ 100.000 y \\
\text { hacen parte } \\
\text { de la nomina } \\
\text { mensual de } \\
\text { operarios. }\end{array}$ \\
\hline $\begin{array}{l}\text { Se encuentra } \\
\text { claramente } \\
\text { definido el } \\
\text { espacio donde se } \\
\text { instalaran los } \\
\text { equipos tecnicos } \\
\text { del subproceso }\end{array}$ & $\begin{array}{l}\text { Garantizar el } \\
\text { correcto } \\
\text { funcionamiento del } \\
\text { proceso. }\end{array}$ & $\begin{array}{l}\text { Señalizar el } \\
\text { area donde se } \\
\text { instalan los } \\
\text { equipos }\end{array}$ & $\begin{array}{l}\text { Personal de } \\
\text { mantenimieto } \\
\text { y logistica de } \\
\text { la empresa }\end{array}$ & $\begin{array}{l}\text { Area de } \\
\text { producción }\end{array}$ & $\begin{array}{l}\text { Durante el } \\
\text { transcurso de } \\
\text { implementación } \\
\text { del subproceso }\end{array}$ & $\begin{array}{l}\$ 50.000 \\
\text { Presupuesto } \\
\text { mantenimien } \\
\text { to }\end{array}$ \\
\hline $\begin{array}{l}\text { El cuarto frio se } \\
\text { encuentra en } \\
\text { buen estado de } \\
\text { funcionamiento y } \\
\text { dentro del area } \\
\text { de procesos }\end{array}$ & $\begin{array}{l}\text { Preservar durante } \\
\text { todo el proceso la } \\
\text { misma temperatura } \\
\text { las proteinas. }\end{array}$ & $\begin{array}{l}\text { Controlando la } \\
\text { puerta de } \\
\text { acceso y el } \\
\text { termometro } \\
\text { digital en la } \\
\text { entrada } \\
\text { principal }\end{array}$ & Operarios & $\begin{array}{l}\text { Area de } \\
\text { producción }\end{array}$ & $\begin{array}{l}\text { Durante el } \\
\text { transcurso de } \\
\text { implementación } \\
\text { del subproceso }\end{array}$ & $\begin{array}{l}\text { \$0ya se } \\
\text { encuentra en } \\
\text { funcionamie } \\
\text { nto }\end{array}$ \\
\hline
\end{tabular}

\begin{tabular}{|c|c|c|c|c|c|c|}
\hline $\begin{array}{l}\text { Control diario de } \\
\text { remanentes de } \\
\text { inventarios en } \\
\text { cuarto frio }\end{array}$ & $\begin{array}{l}\text { Garantizar } \\
\text { abastecimientoy } \\
\text { calidad de los } \\
\text { productos }\end{array}$ & $\begin{array}{l}\text { Registro diario } \\
\text { en libro de } \\
\text { inventariosy } \\
\text { control }\end{array}$ & $\begin{array}{l}\text { Encargado de } \\
\text { producción e } \\
\text { Ingeniero de } \\
\text { alimentos }\end{array}$ & $\begin{array}{l}\text { Area de } \\
\text { producción }\end{array}$ & $\begin{array}{l}\text { De manera } \\
\text { permanente }\end{array}$ & $\begin{array}{l}\text { \$0 porque } \\
\text { hace parte } \\
\text { de las } \\
\text { funciones } \\
\text { asignadas }\end{array}$ \\
\hline $\begin{array}{l}\text { Someter a } \\
\text { estrictos } \\
\text { procedimientos } \\
\text { de calibración de } \\
\text { equipos e } \\
\text { instrumentos de } \\
\text { medición }\end{array}$ & $\begin{array}{l}\text { Asegurar el optimo } \\
\text { funcionamiento de } \\
\text { las herramientas } \\
\text { tecnologicas }\end{array}$ & $\begin{array}{l}\text { Programa de } \\
\text { calibración de } \\
\text { equipos }\end{array}$ & $\begin{array}{l}\text { Administrador } \\
\text { de la empresa }\end{array}$ & $\begin{array}{l}\text { Area de } \\
\text { producción }\end{array}$ & Mensual & $\begin{array}{l}\$ 40.000 \text { del } \\
\text { presupuesto } \\
\text { mantenimien } \\
\text { to }\end{array}$ \\
\hline
\end{tabular}




\section{Ilustración 23 Continuación plan de acción}

\begin{tabular}{|c|c|c|c|c|c|c|}
\hline $\begin{array}{c}\text { ¿Qué se debe } \\
\text { hacer? }\end{array}$ & ¿Por qué se hace? & Como se hace? & $\begin{array}{c}\text { ¿Quién lo } \\
\text { hace? }\end{array}$ & \begin{tabular}{|c|}
$\begin{array}{c}\text { ¿Dónde se } \\
\text { hace? }\end{array}$ \\
\end{tabular} & $\begin{array}{c}\text { ¿Cuándo se debe } \\
\text { hacer? }\end{array}$ & $\begin{array}{c}\text { ¿Cuánto va a } \\
\text { costar? }\end{array}$ \\
\hline $\begin{array}{l}\text { Manual de } \\
\text { operatividad para } \\
\text { el procedimiento } \\
\text { de porcionado }\end{array}$ & $\begin{array}{l}\text { Asegurar } \\
\text { conocimiento y } \\
\text { seguridad dentro } \\
\text { del area de } \\
\text { produción }\end{array}$ & $\begin{array}{l}\text { Entrega de } \\
\text { manual a todo } \\
\text { el personal } \\
\text { tanto operativo } \\
\text { y } \\
\text { administrativo }\end{array}$ & $\begin{array}{l}\text { Coordinación } \\
\text { del proyecto y } \\
\text { el Ingeniero de } \\
\text { alimentos }\end{array}$ & $\begin{array}{l}\text { Area de } \\
\text { producción }\end{array}$ & $\begin{array}{l}\text { Justo antes de } \\
\text { dar inicio al } \\
\text { subproceso de } \\
\text { porcionado }\end{array}$ & $\begin{array}{l}\$ 100.000 \text { del } \\
\text { presupuesto } \\
\text { anual de } \\
\text { capacitación }\end{array}$ \\
\hline $\begin{array}{l}\text { Avisos alusivos al } \\
\text { peligro y cuidado } \\
\text { del manejo de la } \\
\text { sierra el trabajo } \\
\text { en el cuarto frio }\end{array}$ & $\begin{array}{l}\text { Garantizar la } \\
\text { custodia de } \\
\text { temperatura y la } \\
\text { integridad de los } \\
\text { operarios }\end{array}$ & $\begin{array}{l}\text { Instalar avisos } \\
\text { a la entrada y } \\
\text { en lugares de } \\
\text { facil visivilidad } \\
\text { del area } \\
\text { productiva }\end{array}$ & $\begin{array}{l}\text { Coordinación } \\
\text { del proyectoy } \\
\text { el Ingeniero de } \\
\text { alimentos }\end{array}$ & $\begin{array}{l}\text { Area de } \\
\text { producción }\end{array}$ & Inmediato & $\begin{array}{l}\$ 200.000 \text { del } \\
\text { presupuesto } \\
\text { seguridad de } \\
\text { instalaciones }\end{array}$ \\
\hline $\begin{array}{l}\text { Contar con } \\
\text { soporte de } \\
\text { resultados de } \\
\text { laboratorio sobre } \\
\text { la calidad de la } \\
\text { carne }\end{array}$ & $\begin{array}{l}\text { Asegurar inocuidad, } \\
\text { calidady } \\
\text { presentación del } \\
\text { producto elaborado }\end{array}$ & \begin{tabular}{|l} 
Registros \\
secuenciales de \\
los resultados \\
de examenes \\
de laboratorio
\end{tabular} & $\begin{array}{l}\text { Ingeniero de } \\
\text { alimentos }\end{array}$ & $\begin{array}{l}\text { Area } \\
\text { administrat } \\
\text { iva de la } \\
\text { empresa }\end{array}$ & $\begin{array}{l}\text { De manera } \\
\text { trimestral }\end{array}$ & $\begin{array}{l}\$ 90.000 \text { del } \\
\text { presupuesto } \\
\text { anual para } \\
\text { actividades } \\
\text { productivas }\end{array}$ \\
\hline
\end{tabular}

\begin{tabular}{|c|c|c|c|c|c|c|}
\hline $\begin{array}{l}\text { Las porciones se } \\
\text { deben rotular de } \\
\text { conformidad con } \\
\text { la resolución } \\
5109 \text { de } 2005\end{array}$ & $\begin{array}{l}\text { Control de calidad } \\
\text { de materias primas } \\
\text { y demas insumos }\end{array}$ & \begin{tabular}{|l|} 
Rotular \\
materias \\
primas \\
secuencialment \\
e
\end{tabular} & Operarios & $\begin{array}{l}\text { Area de } \\
\text { producción }\end{array}$ & $\begin{array}{l}\text { Durante la } \\
\text { implementación } \\
\text { del subproceso }\end{array}$ & $\begin{array}{l}\$ 50.000 \text { del } \\
\text { presupuesto } \\
\text { anual de } \\
\text { actividades } \\
\text { productivas }\end{array}$ \\
\hline $\begin{array}{l}\text { Politicas } \\
\text { claramente } \\
\text { definidas para la } \\
\text { implementación } \\
\text { de las BPM }\end{array}$ & $\begin{array}{l}\text { Crear una cultura de } \\
\text { BPM en el proceso } \\
\text { productivo }\end{array}$ & $\begin{array}{l}\text { Elaborar } \\
\text { politicas de } \\
\text { calidad }\end{array}$ & $\begin{array}{l}\text { Directivas de } \\
\text { la empresa }\end{array}$ & $\begin{array}{l}\text { Area } \\
\text { administrat } \\
\text { iva de la } \\
\text { empresa }\end{array}$ & Permanente & $\begin{array}{l}\$ 0 \text { Gasto } \\
\text { administrativ } \\
0\end{array}$ \\
\hline
\end{tabular}

[DAE2]

\section{Fuente: Elaboración propia}


El plan de acción está basado en la resolución 2674 de 2013, la ley 1709 de 2014, la Ley 65 de 1993 al igual que la resolución 5109 de 2005, a fin de adaptar cada uno de los pasos concernientes a la creación del subproceso con la legislación Colombiana y con el sentido de responsabilidad inmerso en el presente proyecto.

Otra de las acciones inherentes al proyecto están relacionadas con la elaboración de los indicadores tanto de cumplimiento como los de control, estos se trabajan de manera nominal, con intervalos y de razón para demostrar la importancia de la implementación del subproceso.

Ilustración 24 Indicadores de cumplimiento

\begin{tabular}{|l|l|}
\hline Indicador No.1 & Fuente de verificación \\
\hline $\begin{array}{l}\text { Al finalizar el primer bimestre de } \\
\text { operación se disminuyó en un 85\% } \\
\text { los desperdicios de carnes } \\
\text { contaminadas }\end{array}$ & $\begin{array}{l}\text { Tomando los datos del libro de } \\
\text { registro sobre de los desperdicio de } \\
\text { carne del último bimestre, sobre el } \\
\text { registrado en el mismo periodo del } \\
\text { bimestre anterior }\end{array}$ \\
\hline $\begin{array}{l}\text { Indicador No.2 } \\
\text { en un 5\% las utilidades netas de la } \\
\text { empresa }\end{array}$ & $\begin{array}{l}\text { En el Balance general, se tomas las } \\
\text { utilides del mes y se restan las del } \\
\text { periodo anterior, el resultado } \\
\text { dividido por la utilidad total. }\end{array}$ \\
\hline $\begin{array}{l}\text { Indicador No.3 } \\
\text { A partir del primer mes se reduce a } \\
\text { la mitad el tiempo de porcionado de } \\
\text { carnes }\end{array}$ & $\begin{array}{l}\text { Fuente de verificación } \\
\text { yegistro de nomina de trabajadores }\end{array}$ \\
\hline Indicador No.3 & Fuente de verificación \\
\hline
\end{tabular}




\begin{tabular}{|l|l|}
\hline $\begin{array}{l}\text { Luego del primer semestre se } \\
\text { reduce a } 0 \text { el número de enfermos }\end{array}$ & $\begin{array}{l}\text { Certificación de BPM y registro de } \\
\text { enfermos en el área de sanidad y }\end{array}$ \\
$\begin{array}{l}\text { por causa de alimentos en mal } \\
\text { estado }\end{array}$ & enfermería de la Cárcel \\
\hline
\end{tabular}

Con la ayuda de Microsoft Project 2013, se elabora en diagrama de Gantt en el cual se incluyen todas las tareas desde el plan de trabajo como estudiante de administración de empresas hasta el del plan de ejecución del proyecto en caso de que la propuesta fuese aceptada por la empresa Proalimentos Liber SAS.

\section{Ilustración 14 Diagrama de Gantt}

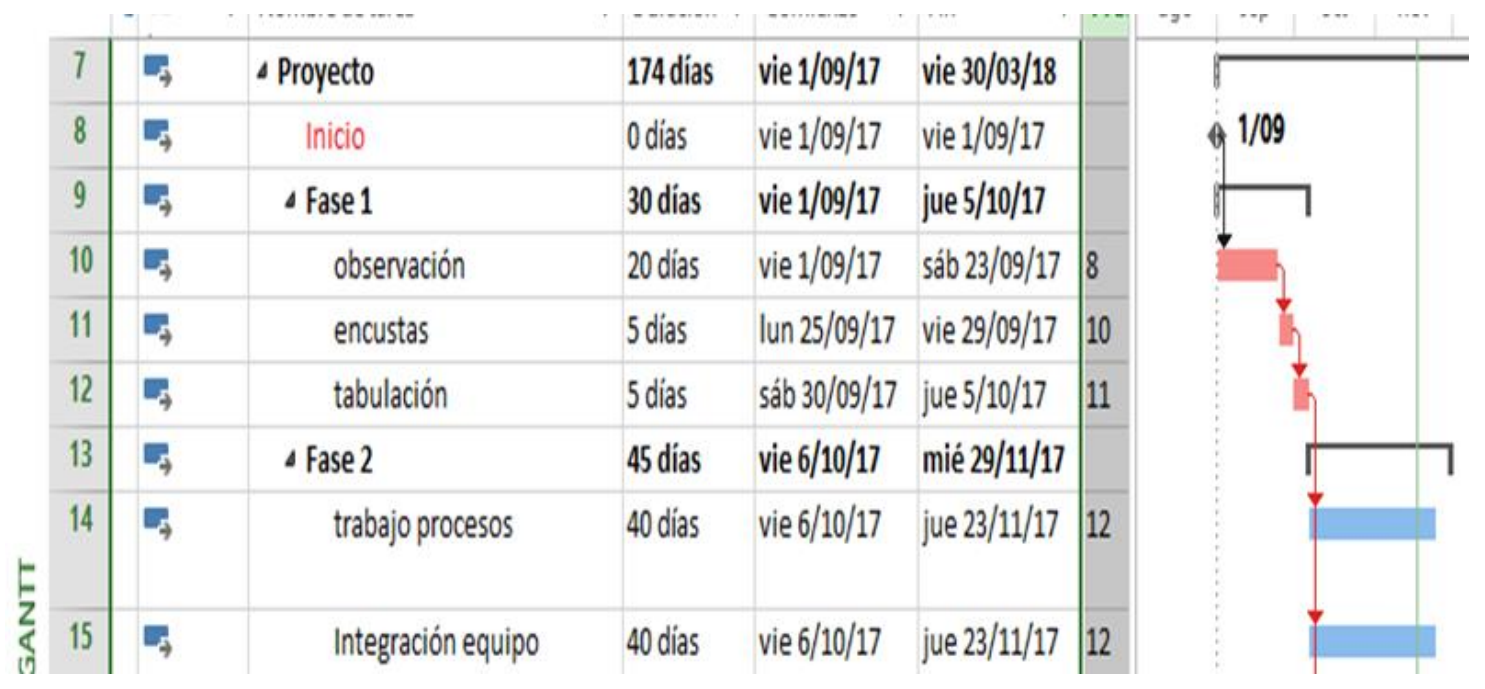




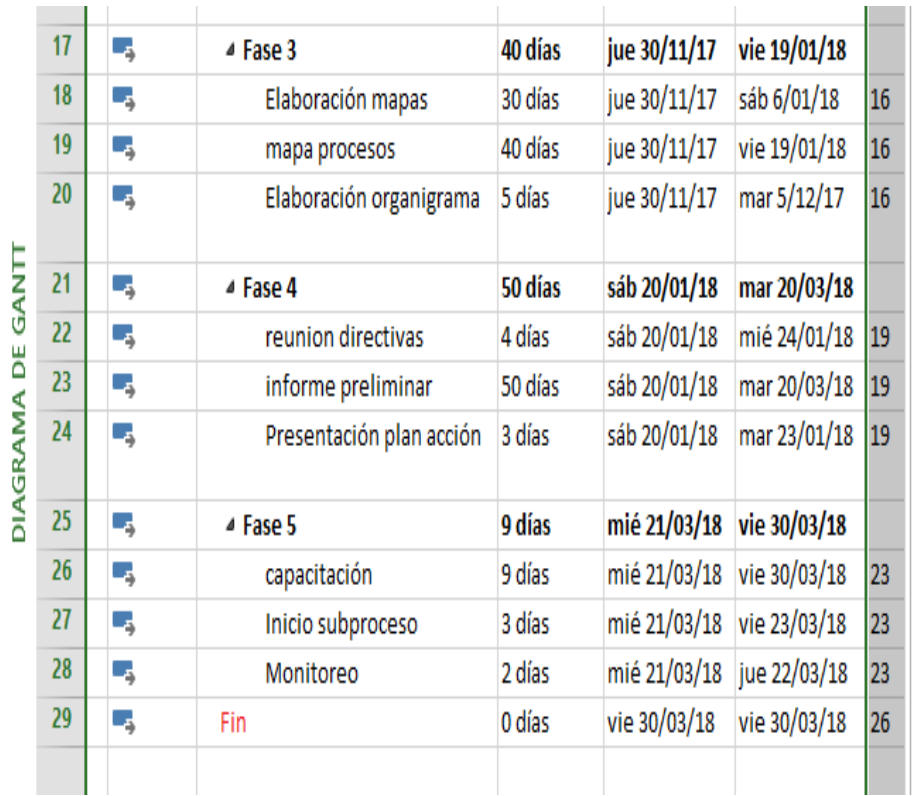

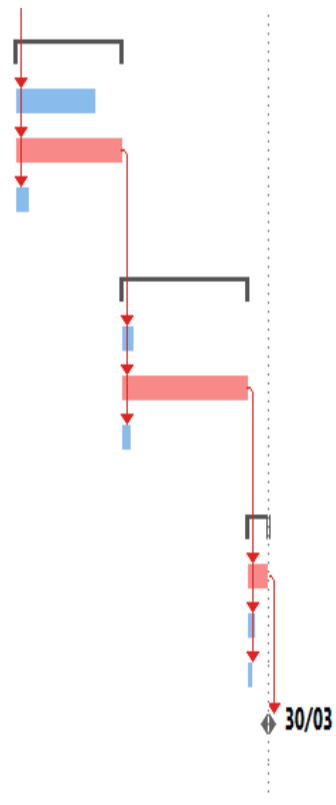

Los costos del proyecto están sustentados en el estudio del subproceso de porcionado de la siguiente manera: Los tres elementos del costo no requiere compra adicional, con relación a la Materia prima recordemos un concepto: "Son todos aquellos que pueden identificarse fácilmente en el producto terminado y representa el principal costo en la elaboración de este producto. Un ejemplo de material directo es la tela que se utiliza en la fabricación de camisas. De igual manera se debe tener en cuenta la unidad, la cantidad de inventarios de estos productos para no quedar la producción detenida, etc" (Benassini, 2014, pág. 156).

Los costos requeridos para implementación esta referenciado con la compra de una sierra circular, que según la indagación realizada su costo promedio está en $\$ 450.000$ y esta incluido dentro de los $\$ 800000$ que se pretende incorporar al presupuesto total para la puesta en marcha del subproceso. A continuación se muestran los precios encontrados en el mercado y que se destacan en páginas de internet así: 


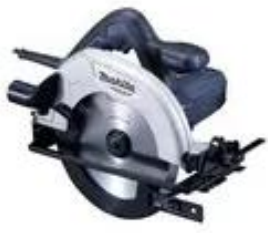

\section{Sierra Circular 7 1/2 Pulg Makita M5802g} por Makita

$\$ 366.900$

Hasta $12 \times \$ 30.575$ sin interés

Wh Envio gratis a todo el país

1 vendido - Bogotá D.C.

\section{Sierra Circular 7 1/4 1450w Bosch} por Easy

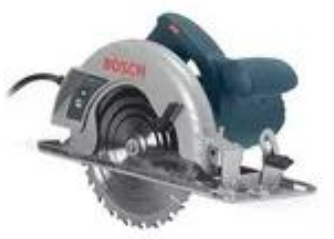

$\$ 529.990$

$36 \times \$ 14.721$

ton Envío gratis a nivel nacional

1 vendido - Bogotá D.C.

Sierra Circular 7 1/4 1400w 5700rpm Skil por Easy

$\$ 239.990$

$36 \times \$ 6.666$

Danvio gratis a nivel nacional

Fuente: Elaboración con datos WWW. mercado libre. com

Estos son los gastos mas importantes que incurre la organización al momento dela implementación del subproceso

\begin{tabular}{|c|c|c|c|c|}
\hline \multicolumn{5}{|c|}{ Muebles y Enseres } \\
\hline Descripción & Un. Medida & Cantidad & Valor Unit. & Total \\
\hline archivadores & Un. & 2,00 & $120.000,00$ & $240.000,00$ \\
\hline & & & & $240.000,00$ \\
\hline \multicolumn{5}{|c|}{ Maquinaria y Equipo } \\
\hline Descripción & Un. Medida & Cantidad & Valor Unit. & Total \\
\hline sierra electrica & Un. & 1,00 & $550.000,00$ & $550.000,00$ \\
\hline & & & & $550.000,00$ \\
\hline
\end{tabular}




\subsection{Integración con el Balanced Score Card|[Udw3]}

Es preciso aclarar en que consiste esta el balanced score card y se puede definir de manera rápida como la herramienta que permite medir, lo intangible, complementar e integrar con la misión y la visión de la empresa; de esta manera se abre una ventana de posibilidades para que Liber logre cumplir con las metas y propósitos trazados desde la alta gerencia.

Para empezar esta labor es claro precisar como la empresa no cuenta con planeación estratégica formal: se definía el presupuesto de acuerdo a estimaciones de mercado y conocimiento directivo, mensualmente se ajusta conforme al resultado de las ventas y no cuenta con un proceso estandarizado de acuerdo al crecimiento del negocio ni con alineación en ningún nivel de la compañía que permitiera medir y evaluar el logro de los objetivos, tampoco existe un BSC empresa

EI BSC busca mejorar las estrategias de la organización. En este caso se debe crear el Balanced teniendo en cuenta el objeto enfocado al subproceso de la empresa y es "Producir y comercializar alimentos para la población en estado de reclusión y eventos empresariales al mejor precio acorde con los mercados, buscando el bienestar y la nutrición de todos los clientes"

En este caso se busca tener en cuenta que la estrategia este encaminada al cumplimiento de los objetivos específicos que son:

- Analizar los problemas operativos de la empresa Pro alimentos Líber S.A.S., a fin de presentar alternativa de solución.

- Identificar los procesos operativos de la empresa Liber para determinar la mejor solución en la implementación de un nuevo subproceso que permita la satisfacción del consumidor.

- Diseñar un subproceso en el proceso de suministro de alimentos para La satisfacción del usuario de la Cárcel La Blanca en la ciudad de ManizalesCaldas. 
A continuación se muestra resumido los elementos estratégicos de la integración del BSC, observando con especial atención como la parte financiera está en la parte superior porque de ella se desprende la mejora continua en la perspectiva del cliente, los procesos internos y por ultimo mirar cómo está el aprendizaje y crecimiento con la ayuda de la retroalimentación.

Se necesita integrar la herramienta estratégica con los objetivos que se trazan en el presente proyecto, para entender a fondo el ámbito de las necesidades que tiene la creación de un subproceso que para el caso es el de porcionado se necesita comprobar que los indicadores mencionados en el punto anterior estén debidamente concatenados y ajustados a la realidad con el Balanced Score card (Cuadro de Mando Integrado), "no han hecho nada más que confirmar que la formulación del futuro y la alineación de toda la organización al cumplimiento de su misión carece de sentido alguno si no se dispone de un sistema de medición ágil" (tesis del balanced score card, 2006, pág. 1).

A continuación aparece la matriz del balanced score card, recordando que áreas como el de monitoreo no se puede medir, porque la organización tiene un nivel de cumplimiento nulo. No existen las auditorias sobre la producción por procesos. En la tabla que se muestra a continuación se plasma la matriz de riesgos, con los hallazgos que se detectaron en las visitas a las instalaciones de la empresa. 
Ilustración 25 Mapa estratégico BSC

\begin{tabular}{|c|c|c|c|}
\hline \multicolumn{4}{|c|}{ Mapa estrategico } \\
\hline OABJETIVOS & METAS & INDICADORES & INICIATIVAS \\
\hline $\begin{array}{l}\text { Perspectiva financiera: } \\
\text { Aumentar los ingresos }\end{array}$ & $\begin{array}{l}\text { Aumentar en un } \\
5 \% \text { la utilidad } \\
\text { neta }\end{array}$ & $\begin{array}{c}\text { Estados } \\
\text { financieros }\end{array}$ & $\begin{array}{l}\text { Desarrollar nuevas } \\
\text { politicas para } \\
\text { modernizar las } \\
\text { herramientas }\end{array}$ \\
\hline $\begin{array}{l}\text { Perspectiva del cliente: } \\
\text { Tener un alto grado de } \\
\text { aceptación del producto }\end{array}$ & $\begin{array}{c}\text { Disminuir a cero } \\
\text { las devoluciones } \\
\text { de comida }\end{array}$ & $\begin{array}{c}\text { Guia de recepción } \\
\text { de comidas } \\
\text { rechazadas en } \\
\text { pabellones }\end{array}$ & $\begin{array}{l}\text { Mejorar los } \\
\text { procedimientos con } \\
\text { el subproceso de } \\
\text { porcionado }\end{array}$ \\
\hline $\begin{array}{c}\text { Perspectiva de los } \\
\text { procesos internos: } \\
\text { Adecuar instalaciones } \\
\text { para mejorar procesos }\end{array}$ & $\begin{array}{l}\text { Disminuir a la } \\
\text { mitad el tiempo } \\
\text { de preparación } \\
\text { de materia prima }\end{array}$ & $\begin{array}{l}\text { Tiempo registrado } \\
\text { en porcionado de } \\
\text { las carnes }\end{array}$ & $\begin{array}{c}\text { Compra de } \\
\text { herramientas como } \\
\text { la sierra electrica }\end{array}$ \\
\hline $\begin{array}{c}\text { Perspectiva de } \\
\text { aprendizaje y } \\
\text { crecimiento: Contar con } \\
\text { operarios altamente }\end{array}$ & $\begin{array}{c}\text { Capacitar al } 100 \% \\
\text { del personal } \\
\text { operativo }\end{array}$ & $\begin{array}{l}\text { Numero de } \\
\text { certificados } \\
\text { adquiridos por } \\
\text { empleados }\end{array}$ & $\begin{array}{l}\text { Estrategias de } \\
\text { capacitación con el } \\
\text { SENA Caldas. }\end{array}$ \\
\hline
\end{tabular}

Fuente: elaboración propía 
|llustración 26 Integración del BSC[DAE4]

\begin{tabular}{|c|c|c|c|}
\hline 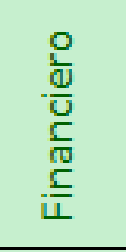 & $\begin{array}{l}\text { Aumentar la } \\
\text { utilidad de la } \\
\text { empresa }\end{array}$ & $\begin{array}{c}\text { Lograr un } 4 \% \\
\text { adicional en las } \\
\text { utilidades de la } \\
\text { empresa }\end{array}$ & $\begin{array}{c}\text { Disminuir en un } 37 \% \\
\text { el desperdicio de los } \\
\text { carnicos }\end{array}$ \\
\hline 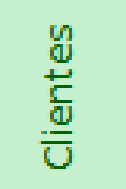 & $\begin{array}{l}\text { Lograr la } \\
\text { satisfacción del } \\
\text { cliente }\end{array}$ & $\begin{array}{c}\text { evitar las quejas y } \\
\text { reclamos de los } \\
\text { consumidores }\end{array}$ & $\begin{array}{c}\text { Alcanzar un } 0 \% \text { en } \\
\text { las devoluciones de } \\
\text { comidas }\end{array}$ \\
\hline 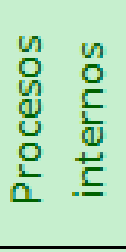 & $\begin{array}{l}\text { Disminuir los } \\
\text { tiempos de } \\
\text { manipulación en } \\
\text { la materia prima }\end{array}$ & $\begin{array}{c}\text { Estandarización de } \\
\text { las porciones de } \\
\text { carnes }\end{array}$ & $\begin{array}{c}\text { tecnificación de los } \\
\text { equipos de trabajo } \\
\text { en el subproceso }\end{array}$ \\
\hline 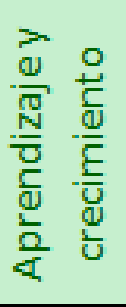 & $\begin{array}{l}\text { Capacitar a } 100 \% \\
\text { de los operarios }\end{array}$ & $\begin{array}{c}\text { Retroalimentación } \\
\text { sobre las } \\
\text { experiencias } \\
\text { exitosas con el } \\
\text { subproceso } \\
\end{array}$ & $\begin{array}{c}\text { Aprovechar } \\
\text { convenios con SENA } \\
\text { Manizales }\end{array}$ \\
\hline
\end{tabular}

Fuente: elaboración propia

La empresa necesita con urgencia implementar una política integral que contenga la creación y puesta en marcha del subproceso de porcionado de manera tal que lo estratégico y lo operativo se unan para aumentar las utilidades netas de la empresa hasta en un $4 \%$ y la disminución de los desperdicios de materia prima (carnes) hasta en un 37\%, siendo la mejor alternativa para solucionar los inconvenientes presentados en el proceso de manipulación de alimentos.

\section{Plan de acción e indicadores conexos al Balanced score card:}

La empresa Liber SAS, enfatiza sus actividades en la preparación de alimentos para empresas del orden gubernamental, para alcanzar la certifiación de BPM, requiere estar en la mejora continua y debe reforzar el proceso de manipulación de alimentos. De no implementar la creación del subproceso de 
porcionado le pueden acarrar turbulencias a la organización y el aumento progresivo de costos de producción.

\section{Ilustración 27 Balanced Score Card}

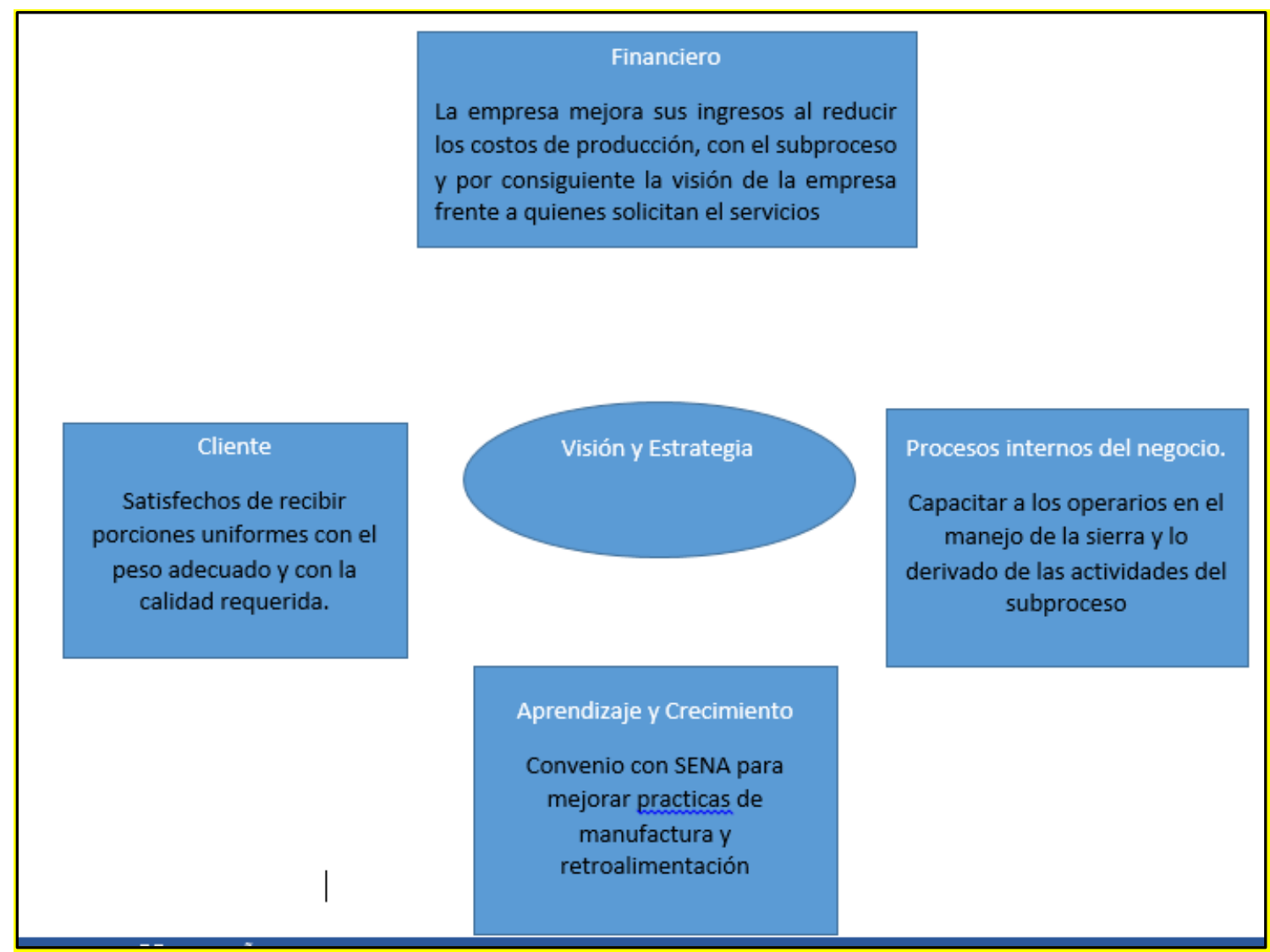

Fuente: Elaboración propia

\subsection{Lecciones aprendidas.}

Las lecciones aprendidas en la elaboración del presente trabajo, son innumerables, las más destacadas tienen que ver con las dificultades presentadas en el proceso de recolección de información, uno de los grandes inconvenientes en el desarrollo de mis estudios profesionales esta referenciado a las restricciones y prohibiciones que existen en el interior de la penitenciaria donde me hallo en calidad de interno, no se puede usar el celular, las redes sociales, el internet, esto limita el acceso a 
la información o a las bases de datos que proporcionan información conducente dentro de la investigación.

En cuanto al trabajo realizado una sede principal no es lo mismo que en una subsede de la organización, es diferente allí la recolección de información pertinente para la práctica, no está o sencillamente no existe y lo poco que hay requiere tramitología con las directivas de la sede principal para que autoricen el acceso a ciertas áreas restringidas, lo mismo que el de las sugerencias que se presentan porque el administrador de la subsede no tiene la autoridad para la toma de decisiones, pues esta empresa en particular presenta el tipo de administración vertical, bloquea los actos que requieren actuar con diligencia.

\section{CONCLUSIONES Y RECOMENDACIONES}

Las recomendaciones que se presentan en el presente proyecto, son el producto de una investigación seria con datos obtenidos a través de técnicas como la entrevistas, la observación y los datos de primera mano; se darán desde el punto de vista proactivo buscando que la empresa se apoye en las recomendaciones dadas y sin que ello con lleve a que la empresa las debe implementar pero si dando la opción siempre a mejorar los procesos en la misma.

Las devoluciones de los alimentos por parte de los clientes consumidores, a causa de insatisfacción por las porciones de carne suministradas alcanzo un $37 \%\left[\right.$ [Udw5] del total de la proteína adquirida por la empresa ${ }^{5}$, para el segundo semestre del año 2017 y con la misma tendencia para el presente año, por ende la empresa necesita mejorar los procesos productivos de una manera que no le representé aumento en costos y por el contrario pueda mejorar calidad y disminuir las pérdidas de materia prima (cárnicos) hasta llegar a 4\% con la inclusión del subproceso de porcionado. Se puede dar cumplimiento a las metas, dentro de las

\footnotetext{
${ }^{5}$ Tomado de la Minuta interna de LIBER S.A. el segundo semestre de 2017.
} 
próximas 36 semanas; con la implementación de la propuesta, se sugiere implementarlo en el proceso de manipulación de alimentos.

Una vez finalizadas y cumplidas, las recomendaciones, es aconsejable, monitorear y auditar las actividades realizadas dentro del proceso operativo que se lleva dentro de la bodega de almacenamiento y cuarto frio. Los cinco componentes productivos (compras, técnico, producción, talento humano ventas y administración) deben funcionar de manera integrada para reducir a un nivel aceptable el riesgo de no alcanzar el objetivo principal de la organización que es lograr mantener la licitación con el Estado durante los próximos cuatro años.

Los estándares de manejo de materia prima en la organización deben ser regularmente monitoreados, también a los proveedores de servicios externos. Para certificar en todo momento la calidad en la cadena de frio, Las conductas inapropiadas de estos proveedores pueden reflejarse negativamente en la Alta Dirección e impactar a la entidad hasta causar daño en los clientes en su salud o la reputación misma de la entidad. Es importante que existan canales de comunicación, ya sean formales o informales, para que el personal pueda reportar las irregularidades que se presenten.

El Área de Recursos Humanos de la organización puede ayudar en la definición de la competencia y niveles de personal para los puestos de trabajo, facilitando la capacitación y evaluación de la relevancia e idoneidad del desarrollo profesional individual en relación con las necesidades de la organización. 


\section{BIBLIOGRAFÍA}

Bejarano, Jhon Jairo, C., Carlos Augusto, S., \& Lilianaa. (2015). Alimentación penitenciaria: entre higiene y derechos . Bogotá D.C.: Universidad Nacional.

Benassini, M. (2014). Introducción a la investigación de mercados. Mexico: Pearson.

BERNAL, A. C. (2010). METODOLOGIA DE LA INVESTIGACIÓN. BOGOTÁ D.C.: PEARSON EDUCACIÓN.

Caracas se mantiene como la capital más violenta del mundo. (28 de Diciembre de 2016). Obtenido de www.el-nacional.com > Sucesos

Carcelario, I. N. (15 de octubre de 2017). Organización en linea. Obtenido de http://www.inpec.gov.co/portal/page/portal/inpec

Chiavenato, I. (1993). Iniciación a la Administración de Produccióneoria de la producción. Mexico: McGraaw - Hill Interamericana.

Choo, W. (2000). La organización inteligente. Mexico: Oxford.

Colanta. (2012). Cooperativa Colanta. Obtenido de Colanta: http://cooperativismoysolidaridad.blogspot.com.co/2012/0

Colanta. (17 de octubre de 2017). Logros de colanta. Obtenido de www.colanta.com

Desplome de las relaciones comerciales. (12 de diciembre de 2016). Obtenido de https://www.elheraldo.co/local/lo-que-esta-en-juego-en-la-crisis-con-venezuela-214448

Di Marco, F. (1935). Operaciones contables. Milan: Marequeti.

Frisby. (febrero de 2007). Frisby sa. Obtenido de repositorio Frisby: repositorio.utp.edu.co/dspace/bitstream/handle/11059/781/658406B328pm.pdf;...

Gaviria Uribe, A. (2013). Resolucióno 2674. Bogotá.

Hillier, F., \& Hillier, M. (2010). Metodos Cuantitativos Para La Administración. Mexico D.F.: McGraw - Hill Interamericana.

Inversiòn extrtanjera. (12 de enero de 2006). Recuperado el 03 de abril de 2017, de www.inversiòn extranjera de portafolio: http://www.inversiòn extranjera.com

Liber. (2017). Proalimentos Liber SAS. Obtenido de Liber: www.liber.com

Manual de Manipulación de Alimentos, M4-S2-MA-01 (Unidad de Servicios Penitenciarios y Carcelarios 17 de Julio de 2014).

Marco, J. A. (2017). proceso operativo en almacen. Obtenido de https://www.imfformacion.com/blog/logistica/logistica/procesos-operativos-almacen/

Peña, B. R. (2017). PESEM. Balance social. Bogotá: Usta.

RENDER, J. H. (2007). DIRECCION DE LA PRODUCCIÒN Y DE OPERACIONES. madrid: PEARSON.

Republica, P. d. (1997). Decreto 3075. En P. d. Republica. Bogotá D.C. 
Robbins, s., \& Judge, T. (2017). Comportamiento Organizacional. Mexico: Pearson.

RODRIGUEZ, J. A. (1 de enero de 2014). "motivos para hablar de cibercultura". Obtenido de "GNU Free Documentation License": http://es.wikibooks.org/wiki/Cibercultura.

Salud, M. d. (2013). Decreto 2674. Bogotá: Ministerio.

Samper, D. (2014). La crisis carcelaria en Colombia. Semana, 24-25.

Sapag, N., Sapag, R., \& Sapag, j. M. (2014). Preparación y evaluación de Proectos. Mexico, D.F.: Mac Graw Hill.

Sarmiento, J. (2017). Libro de Contabilidad. Manizales.

Social, M. d. (2013). Decreto 2674. Bogotá D.C.

TAYLOR, F. W. (1911). Principios de la administración cientifica. Barcelona: Orbis.

tesis del balanced score card. (2006). Obtenido de https://www.dspace.espol.edu.ec/.../TESIS\%20DEL\%20BALANCED\%20SCORECAR

Toro, B. (2002). Responsabilidad social. Bogotá.

wikipedia. (s.f.). Obtenido de www.wikipedia.

Zaratiegui, J. (1999). La gestión por Procesos. economia Industrial, 86-90. 


\section{Anexo}

\section{Formato encuesta}

Nombre td.........

Patio

1. ¿Cómo puede mejorar el servicio de alimentación que presta la empresa Líber S.A.S. en la cárcel de varones de la ciudad de Manizales?

Respuesta

2. ¿Cuáles son los insumos que más se desperdician en la porción de comida que recibe?

Respuesta

3. Como le parece el suministro de alimentos?
a. Excelente
b. regular
c. deficiente
d. malo

4. ¿Cómo le parece la calidad de la proteína que consume?
a. Excelente
b. regular
c. deficiente d. malo

5. Las raciones de proteína que recibe son uniformes?
a. siempre
b. casi siempre
c. casi nunca
d. nunca

6. ¿le gustaría que las porciones de proteínas fueran iguales?
a. si
b. no

7.

¿Cómo valoras la calidad de nuestra comida?

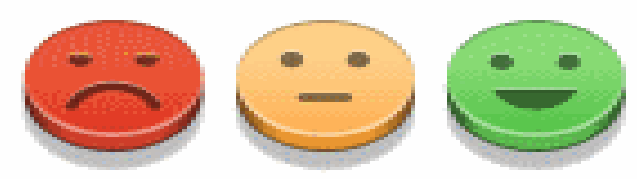

¿Cómo valorarías la atención del personal que te sirvió?
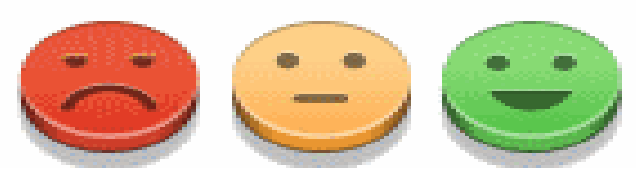
